\title{
Efectos de las políticas de recursos humanos socialmente responsables en el capital intelectual
}

\author{
Jesus Barrena-Martínez (iD, Macarena López-Fernández (iD), Pedro Miguel Romero-Fernándezii \\ Universidad de Cádiz (Spain) \\ jesus.barrena@uca.es, macarena.lopez@uca.es, pedrom.romero@uca.es
}

Received November, 2015

Accepted January, 2016

\section{Resumen}

Objeto: La presente investigación se centra en los beneficios que la responsabilidad social puede reportar al área de recursos humanos, examinado el impacto que una configuración de políticas y prácticas de recursos humanos socialmente responsable tiene en la generación de valor de la empresa, y más concretamente en su capital intelectual.

Diseño/metodología/enfoque: El estudio realiza un análisis de regresión, testando los efectos individuales de las políticas de recursos humanos socialmente responsables en el capital intelectual, desglosado en tres variables principales como son capital humano, social y organizacional.

Aportaciones y resultados: Los resultados del estudio arrojan luz sobre cómo la introducción de aspectos socialmente responsables en la gestión de los recursos humanos puede facilitar el intercambio de conocimientos, habilidades y actitudes -capital humano-; inducir a mejoras en la comunicación, confianza, cooperación entre los empleados - capital social- y, a su vez, generar un conocimiento institucionalizado codificado en la propia cultura organizativa -capital organizacional-.

Limitaciones: El estudio solo proporciona información de grandes empresas de más de 250 empleados. 
Implicaciones prácticas: Existen importantes repercusiones en lo que a la medida de la responsabilidad social corporativa se refiere en el área de recursos humanos.

Implicaciones sociales: Asimismo, se confirman importantes efectos sobre variables intangibles de carácter no económico, como es el caso del capital intelectual.

Originalidad / Valor añadido: El valor del estudio reside en su novedad, testando configuraciones de recursos humanos socialmente responsables, así como los efectos directos de las diferentes políticas en el capital intelectual.

Palabras clave: Capital Intelectual, Gestión de Recursos Humanos, Políticas de Recursos Humanos Socialmente Responsables, Capital Humano, Capital Social, Capital Organizacional

Códigos JEL: M12, O34

Title: Impact of socially responsible human resources policies on intellectual capital

\section{Abstract}

Purpose: This research focuses on the benefits that social responsibility can report on the area of human resources, examined the impact of a socially responsible configuration of human resource policies and practices in the generation value process for the company, and more specifically in its intellectual capital.

Design/methodology: The study performed a regression analysis, testing the individual effects of socially responsible human resource policies on intellectual capital, broken down into three main variables such as human, social and organizational capital.

Findings: The results shed light on how the introduction of socially responsible aspects in the management of human resources can facilitate the exchange of knowledge, skills and attitudes -human capital-; lead to improvements in communication, trust, cooperation among employees -social-capital- and, in turn, generates an institutionalized knowledge encoded in the own organizational culture -organizational capital-

Research limitations/implications: The study only provides information from large companies with over 250 employees.

Practical implications: There are important implications in the measure of corporate social responsibility concerns in the area of human resources. 
Social implications: Also important intangible effects on non-economic variables are confirmed, such as intellectual capital.

Originality/value: The value of the study lies in its novelty, testing socially responsible configurations of human resources as well as the direct effects of different policies on intellectual capital.

Keywords: Intellectual capital, Human Resource Management, Socially Responsible Human Resource Policies, Human capital, Capital stock, Organizational Capital

Jel Codes: M12, O34

\section{Introduction}

En el nuevo contexto de competitividad actual, las empresas son conscientes de que ofrecer un valor diferencial, que facilite las relaciones con los grupos de interés que componen su entorno, resulta primordial para su supervivencia y éxito en el mercado (Svensson \& Wood, 2011).

Los enfoques económicos clásicos, que basan el éxito organizativo en la maximización del beneficio a corto plazo o el mejor retorno para el accionista, resultan ahora insuficientes para garantizar la sostenibilidad y rentabilidad continuada de las compañías (Carroll, 1999). El mercado y las partes implicadas en las actividades diarias de la empresa, no solo recompensan a las compañías más poderosas y competitivas en términos económicos, sino que también consideran fundamental la forma y el procedimiento por el cual estos beneficios han sido obtenidos (Freeman \& Liedtka, 1991). Al hilo de esta exigencia actual para las empresas, la Responsabilidad Social Corporativa (RSC) viene proclamándose en los últimos años como una herramienta clave, que ayuda a las compañías a responder a las presiones del entorno y mejorar su competitividad (Carroll \& Shabana, 2010). Adoptando la definición de la Comisión Europea de RSC, entendida como "el proceso de integración en las actividades organizativas de las preocupaciones sociales, medioambientales, éticas y hum anas de sus grupos de interés, con un doble objetivo:

- maximizar la creación de valor para estas partes; e

- identificar, prevenir y mitigar los efectos adversos de las acciones organizativas sobre el entorno" (Comisión Europea, 2011: pp. 6), las empresas que quieran lograr el respaldo 
equilibrado de sus grupos de interés, deberían poner en práctica comportamientos más responsables en la gestión de sus actividades.

La presente investigación, aborda este último aspecto, en concreto, centrándose en los beneficios que la responsabilidad social puede reportar al área de recursos humanos.

Los trabajos en el ámbito de la gestión de los recursos humanos (GRH) han ayudado a la comprensión y definición de sistemas, políticas y prácticas de recursos humanos eficaces desde un punto de vista Intra-organizativo. Sin embargo, resulta necesario examinar la interacción que un fenómeno de repercusión económica, social y medioambiental como el de la responsabilidad social puede ejercer sobre la función de recursos humanos, por el amplio número de grupos de interés que demandan a las empresas la implantación y generalización de estos comportamientos responsables. En este sentido, son pocos los estudios que analizan la relación entre la función de GRH y la responsabilidad social corporativa, a pesar de la importancia que viene cobrando la visión social en la gestión empresarial (Buciuniene \& Kazlauskaite, 2012). Ante esta circunstancia, y bajo la convicción personal de que integrar una orientación socialmente responsable en la gestión de recursos humanos destinada a mejorar la calidad de vida y bienestar de los empleados, sus familias y los miembros de la comunidad en que opera puede mejorar los resultados de las empresas, la presente investigación trata de responder a la siguiente cuestión de investigación: ¿Integrar una orientación socialmente responsable en la gestión de los recursos humanos (configuraciones, políticas y prácticas) puede proporcionar mejoras en los resultados de la empresa?

Para llevar a cabo este objetivo, a continuación se examina el efecto directo de una configuración de políticas y prácticas de recursos humanos calificada como socialmente responsable en el proceso de generación de valor de la empresa, y más concretamente en la variable capital intelectual.

\section{Revisión de la literatura y marco teórico}

Durante un largo período de tiempo las organizaciones han destacado en la sociedad por llevar a cabo un papel, fundamentalmente económico, en el desarrollo de su actividad, contribuyendo de manera activa en la distribución de bienes y servicios, y en la generación de riqueza y empleo (Phillips, Freeman \& Wicks, 2003). Sin embargo, en las últimas décadas, circunstancias como el creciente número de abusos empresariales en el terreno fiscal, el aumento de las desigualdades sociales en el mundo, el gran poder que ostentan las multinacionales, y el deterioro medioambiental acusado por el planeta, han generado que las partes afectadas por las decisiones y resultados organizativos -stakeholders(accionistas, empleados, sindicatos, clientes, proveedores, ciudadanos, comunidad local, Gobierno, etc.), 
requieran a las empresas la consideración de un mayor compromiso y responsabilidad derivada de sus actuaciones (Werther \& Chandler, 2010).

Ante estos requerimientos, y apoyándose en los fundamentos de la teoría institucional, que sostiene que las compañías deben legitimar su actuación si quieren sobrevivir en el mercado, las organizaciones están adaptando sus comportamientos y políticas a los procedimientos, normas y valores demandados por el entorno (Dacin, Kostova \& Roth, 2008). De esta forma, las empresas han pasado de desempeñar únicamente un rol económico, a ejercer una función complementaria de carácter social y medioambiental, enfocada a lograr una mejora en la calidad de vida y bienestar de las personas y grupos involucrados en sus operaciones (Barreto \& Baden-Füller, 2006; Scherer \& Palazzo, 2011). Esta triple consideración de los impactos económicos, sociales y medioambientales en los resultados organizativos -triple bottom line- (Elkington, 1998), se refleja en la creciente elaboración de informes de sostenibilidad por parte de las compañías, que tratan con este proceso de justificar y proporcionar una mayor transparencia de sus acciones antes sus diversos grupos de interés (Shauki, 2011).

Tras examinar un amplio cuerpo de corrientes teóricas, y con objeto de sistematizar el conocimiento, se ha considerado conveniente abordar el estudio e importancia de la responsabilidad para las empresas desde dos enfoques concretos: la teoría institucional y la teoría de stakeholders.

\subsection{Enfoque Institucional}

Durante décadas, las acciones y estrategias organizativas se han ido adaptando a los requerimientos y presiones del entorno (Fernández-Allés \& Valle-Cabrera, 2006). En este sentido, responder al contexto en el que las empresas desarrollan su actividad, así como tratar que sus acciones guarden consonancia con los comportamientos y principios demandados por su entorno se considera vital para la supervivencia organizativa (Dacin, 1997; Scott, 2007). Este proceso relacionado con la interiorización de un conjunto de normas, creencias, valores y principios aceptados por la sociedad y la comunidad en la que se desenvuelven las compañías, conocido como legitimidad, permite acceder de manera más eficiente a los recursos procedentes del entorno $-v$. gr. financiación de inversores y accionistas, apoyo de instituciones públicas y gubernamentales, incremento de las ventas y fidelidad de sus clientes, acceso a negociación de contratos con proveedores y distribuidores, obtención del respeto y compromiso de los empleados - (Barreto \& Baden-Fuller, 2006).

Atendiendo a las ideas expuestas, resulta vital que las compañías adapten sus estrategias, políticas y prácticas a los aspectos socialmente responsables demandados por el entorno, actuales y futuros 
empleados, circunstancia que puede permitirles obtener un valor añadido derivado, así como un mayor compromiso y satisfacción por parte de estos grupos.

Además de la necesidad de responder a las demandas del entorno institucional, existe un enfoque teórico que proclama, como factor esencial de la responsabilidad social, su capacidad para dar respuesta a la gran cantidad de agentes implicados en la actividad empresarial, aspecto que puede condicionar sus resultados (Freeman, 1984; Greenwood \& Anderson, 2009). Este hilo argumental, representa la aportación principal de la teoría de stakeholders, enfoque complementario y necesario para la justificación del modelo teórico del artículo.

\subsection{Enfoque de stakeholders}

El desarrollo de la perspectiva de stakeholders supone la transformación de la relación bilateral, tradicionalmente establecida entre empresa, accionistas y/o propietarios, en otra multilateral, que incorpora a todos los actores implicados en el proceso de desarrollo y gestión organizativa: empleados, sindicatos, clientes, proveedores, administraciones públicas, inversores, medios de comunicación, competidores, comunidad local, etc. (Donaldson \& Preston, 1995; Freeman, Harrison, Wicks, Parmar \& De Colle, 2010).

Ante la multitud de partes implicadas en las actividades organizativas, autores como el propio Freeman, plantean la necesidad de que las organizaciones diferencien y prioricen a la hora de atender las demandas provenientes de estos grupos, en función de su vinculación con la empresa en dos categorías:

- grupos primarios, si poseen un contrato formal con la organización, y resultan imprescindibles para su buen funcionamiento (propietarios, accionistas, empleados, sindicatos, clientes, proveedores, etc.), y

- grupos secundarios, si a pesar de no estar directamente involucrados en sus actividades económicas, no teniendo relación contractual con la misma, pudieran ejercer algún tipo de influencia significativa sobre la misma (ciudadanos, competidores, comunidad local, Gobierno, Administraciones Públicas, etc.).

Considerando las aportaciones e implicaciones de la responsabilidad social para los empleados, como uno de los grupos determinantes en el éxito organizativo, esta investigación pretende aclarar si una orientación socialmente responsable en la gestión de los recursos humanos puede entrañar mejoras en el rendimiento organizativo. Concretamente, algunos estudios recogen como las acciones de responsabilidad social presentan efectos directos sobre variables dependientes de desempeño como: 
- la generación de un mayor sentimiento de pertenencia a la empresa (Cohen-Charash \& Spector, 2001; Kim, Lee, Lee \& Kim, 2010);

- el aumento de los niveles de confianza y compromiso con la empresa (Brammer, Millington \& Rayton, 2007);

- la satisfacción laboral de los trabajadores (Galbreath, 2010); y

- el aumento de la participación de los empleados (Peloza \& Shang, 2011).

Con estos trabajos se vislumbran importantes implicaciones en el análisis de los efectos directos e indirectos que las actividades de responsabilidad social pueden entrañar en el ámbito de la gestión de recursos humanos. Para una adecuada explicación de esta relación, se plantea una perspectiva integrada sobre la base de las perspectivas de stakeholders e institucional, rubricada en un enfoque que cada vez adquiere más importancia por la relevancia del entorno en el ámbito de la GRH, la perspectiva contextual.

\subsection{Enfoque integrado de Gestión de Recursos Humanos Socialmente Responsable}

La integración de diferentes enfoques de investigación utilizados en el ámbito de la GRH, que ayuden a explicar la importancia y efectos sinérgicos de incorporar una orientación socialmente responsable en las políticas y prácticas de recursos humanos será el objetivo de análisis de este epígrafe.

Para una mejor comprensión del ajuste con el contexto, el papel que ejercen las presiones institucionales y los requerimientos de los grupos de interés sobre dicho sistema se consideran claven los planteamientos de la perspectiva contextual (Brewster, 1999; Ferris, Arthur, Berkson, Kaplan, Harrell-Cook \& Frink, 1998; Jackson \& Schuler, 1995), pues ayudan a identificar dos variables claves que componen el entorno y afectan al sistema de GRH socialmente responsable: el contexto socioeconómico (marco regulatorio, legal, político, institucional, social, económico y medioambiental, ámbito cultural, sindicatos y sistema educativo) y el contexto organizativo (clima laboral, cultura, tamaño de la empresa, tecnología, innovación e intereses de determinados grupos).

Así, concretamente, dentro de las variables que componen el contexto socioeconómico, y de acuerdo con autores como Bigné, Chumpitaz, Andreu and Swaen (2005) o Dahlsrud (2008), se aprecia que los comportamientos de responsabilidad social han venido experimentando en las últimas décadas una mayor regulación en el seno de las empresas. Entre las principales iniciativas reguladoras de RSC a nivel internacional destacan el Pacto Mundial de las Naciones Unidas, las directrices de la OCDE, y a nivel europeo el Libro Verde de la Unión Europea sobre RSC y la Estrategia de Desarrollo Sostenible de la 
Unión Europea (2011). Con relación a la proposición de estándares internacionales que permitan la regulación y acreditación de prácticas de RSC destacan el GRI y la ISO 26000 dada su mayor implantación entre las empresas (Marimon, Alonso-Almeida, Rodríguez \& Cortez Alejandro, 2012). En el marco político hay que subrayar, siguiendo a Fuentes-Ganzo (2006), que la propia Constitución Española de 1978, y otras legislaciones a nivel nacional, enfatizan en la importancia de promover comportamientos socialmente responsables organizativos como la Ley de protección de consumidores y usuarios 26/84, la Ley 4/1989 de 27 de Marzo de Conservación de los Espacios Naturales o la Ley 38/1995 de 12 de Diciembre sobre el Derecho de Acceso a la información en materia de Medio Ambiente. A estas iniciativas se suma en 2005 la Subcomisión Parlamentaria para potenciar y promover la responsabilidad social de las empresas a través de la creación del Libro Blanco de la Responsabilidad Social Empresarial. La influencia de este marco político, legal y regulatorio, afecta de manera determinante sobre el amoldamiento y transformación de las políticas y prácticas de recursos humanos en las empresas. De las aportaciones puede detraerse la necesidad de ajuste de la estrategia de recursos humanos, que se plantea como socialmente responsable, con estos factores contextuales de los que se derivarán resultados más eficaces y coherentes a través del desarrollo de diferentes políticas y prácticas de recursos humanos socialmente responsables.

\section{Modelo Conceptual e hipótesis de investigación}

La presente propuesta de investigación va encaminada a la consecución de cuatro objetivos concretos:

- la identificación y contraste académico de un conjunto de mejores políticas y prácticas de recursos humanos socialmente responsables;

- la explicación del ajuste necesario entre estas políticas y prácticas, y los diversos factores contingentes internos de la empresa;

- la propuesta de una configuración de recursos humanos que integre una orientación socialmente responsable en sus políticas y prácticas, analizando cómo la interacción de las mismas puede producir un mayor efecto directo sobre el proceso de generación de valor para la organización; y

- el examen de la influencia de las variables que componen el contexto de la empresa, sobre el diseño de esta configuración de políticas y prácticas de recursos humanos socialmente responsables. 
Una vez planteada esta idea, la cuestión a tratar es: qué políticas y prácticas de recursos humanos son las que deben considerarse, y qué orientación social se les debe dar. Para acometer este objetivo, y construir una base sólida para el desarrollo de estas políticas y prácticas de recursos humanos socialmente responsables, se tomó como referencia:

- la literatura de recursos humanos y responsabilidad social revisada;

- la información depositada en las memorias de responsabilidad social de las empresas del IBEX35 para la identificación de políticas y prácticas socialmente responsables;

- la propuesta de dos índices sociales que han adquirido en los últimos años un gran consenso en la literatura por su importancia para entender los comportamientos socialmente responsables en las diferentes áreas de gestión organizativa: el Global Reporting Initiative (GRI) y la ISO26000.

De la literatura de recursos humanos, se observaron patrones comunes en prácticas de alto rendimiento con matices de interés social, destacando el marco de estudios de la literatura de las High Performance Work Systems y los trabajos de Huselid (1995) y Pfeffer (1998) como se adjuntan en la Tabla 1.

\begin{tabular}{|l|l|l|l|}
\hline Autores & \multicolumn{1}{|c|}{ Variable independiente sistémica } \\
$\begin{array}{l}\text { Walton } \\
\text { (1985) }\end{array}$ & $\begin{array}{l}\text { Sistema de compromiso: } \\
\text { - Diseño de puestos de trabajo; } \\
\text { - Evaluación del desempeño; } \\
\text { - Gestión organizativa (estructura, } \\
\text { sistemas y estilo); } \\
\text { - Compensación; } \\
\text { - Seguridad en el empleo; } \\
\text { - Políticas de participación de los } \\
\text { trabajadores y } \\
\text { - Relaciones laborales. }\end{array}$ & $\begin{array}{l}\text { Desempeño individual: } \\
\text { compromiso empleado }\end{array}$ & $\begin{array}{l}\text { El sistema de compromiso mejora el } \\
\text { desempeño individual de los trabajadores, } \\
\text { gracias a la autorregulación de su } \\
\text { conducta, el establecimiento de confianza } \\
\text { mutua, la responsabilidad compartida por } \\
\text { el grupo de trabajo, la minimización de las } \\
\text { diferencias de estatus, la ampliación de } \\
\text { contenidos del puesto de trabajo y la } \\
\text { combinación de actividades de ejecución y } \\
\text { planificación. }\end{array}$ \\
\hline $\begin{array}{l}\text { Huselid } \\
(1995)\end{array}$ & $\begin{array}{l}\text { Prácticas de recursos humanos de alto } \\
\text { compromiso: } \\
\text { - el reclutamiento y selección del } \\
\text { personal, } \\
\text { - evaluación del desempeño, } \\
\text { los incentivos, el diseño del puesto, } \\
\text { - el manejo de quejas y conflictos, } \\
\text { - el proceso de compartir información, } \\
\text { - la evaluación de las actitudes, } \\
\text { - el manejo de las relaciones de laborales, } \\
\text { - el tiempo dedicado al entrenamiento, } \\
\text { - así como el uso de metodologías para la } \\
\text { promoción.) }\end{array}$ & $\begin{array}{l}\text { Desempeño financiero } \\
\text { de la empresa }\end{array}$ & $\begin{array}{l}\text { Encuentra una relación positiva entre } \\
\text { prácticas de recursos humanos de alto } \\
\text { compromiso para empresas de diferentes } \\
\text { sectores, y su desempeño financiero. Se } \\
\text { obtuvieron otras relaciones positivas } \\
\text { derivadas como la reducción de rotación } \\
\text { de personal y el incremento de su } \\
\text { productividad. }\end{array}$ \\
\hline
\end{tabular}




\begin{tabular}{|c|c|c|c|}
\hline Autores & Variable independiente sistémica & Variable dependiente & Conclusiones \\
\hline $\begin{array}{l}\text { Delaney } \\
\text { y Huselid } \\
(1996)\end{array}$ & $\begin{array}{l}\text { Prácticas de recursos humanos: } \\
\text { - la selección del personal, } \\
\text { - el entrenamiento y formación, } \\
\text { - los incentivos, procedimientos para el } \\
\text { manejo de quejas y conflictos, } \\
\text { - la descentralización en la toma de } \\
\text { decisiones, } \\
\text { - la promoción interna y el uso de una } \\
\text { estructura organizacional jerárquica o } \\
\text { aplanada.) }\end{array}$ & $\begin{array}{l}\text { Compromiso, } \\
\text { implicación y } \\
\text { desarrollo de los } \\
\text { empleados }\end{array}$ & $\begin{array}{l}\text { Manifiestan que el uso de una serie de } \\
\text { mejores prácticas de recursos humanos } \\
\text { ayuda a generar un mayor compromiso, } \\
\text { implicación y desarrollo de los empleados, } \\
\text { apoyando la hipótesis de que determinadas } \\
\text { prácticas puede generalizarse y obtener } \\
\text { beneficios similares en otras } \\
\text { organizaciones. }\end{array}$ \\
\hline $\begin{array}{l}\text { Delery y } \\
\text { Doty } \\
(1996)\end{array}$ & $\begin{array}{l}\text { Prácticas de recursos humanos } \\
\text { independientes: evaluación del desempeño } \\
\text { basada en el resultado de los trabajadores, } \\
\text { seguridad en el trabajo y reparto de tareas } \\
\text { entre los empleados. }\end{array}$ & Desempeño financiero & $\begin{array}{l}\text { Hallan una relación positiva entre el uso de } \\
\text { determinadas prácticas de recursos } \\
\text { humanos, y la mejora del desempeño } \\
\text { financiero de la organización. }\end{array}$ \\
\hline $\begin{array}{l}\text { Guest } \\
(1997)\end{array}$ & $\begin{array}{l}\text { Prácticas de alto rendimiento: } \\
\text { - Selección; } \\
\text { - Socialización; } \\
\text { - Formación y desarrollo profesional; } \\
\text { - Programas de mejora; } \\
\text { - Igualdad estatus; } \\
\text { - Seguridad en el puesto; } \\
\text { - Promoción interna; } \\
\text { - Sistemas de incentivos individuales; } \\
\text { - Comunicación; } \\
\text { - Implicación laboral; } \\
\text { - Trabajo en equipo; } \\
\text { - Diseño de puestos y } \\
\text { - Descripción flexible de puestos. }\end{array}$ & $\begin{array}{l}\text { Desempeño } \\
\text { organizativo: } \\
\text { cumplimiento } \\
\text { objetivos organizativos } \\
\text { y mejora de la } \\
\text { productividad. }\end{array}$ & $\begin{array}{l}\text { Las prácticas de alto rendimiento tienen } \\
\text { efectos concretos sobre el } \\
\text { comportamiento individual y colectivo de } \\
\text { los trabajadores. Así, se traducen en } \\
\text { mayores niveles de motivación, esfuerzo, } \\
\text { cooperación y productividad apreciándose } \\
\text { en la reducción de las tasas de absentismo, } \\
\text { rotación de personal, conflictos internos y } \\
\text { el número de quejas de los clientes. }\end{array}$ \\
\hline $\begin{array}{l}\text { Pfeffer } \\
(1998)\end{array}$ & $\begin{array}{l}\text { Sistema de prácticas de éxito: } \\
\text { - Seguridad en el empleo; } \\
\text { - Cuidado selectivo del proceso selección; } \\
\text { - Uso de equipos auto gestionados y } \\
\text { descentralización de los mismos; } \\
\text { - Compensación elevada vinculada a } \\
\text { resultados empresa; } \\
\text { - Inversión en formación; } \\
\text { - Reducción de las diferencias de estatus y } \\
\text { - Compartir información financiera y de } \\
\text { los resultados con los empleados. }\end{array}$ & $\begin{array}{l}\text { Desempeño } \\
\text { organizativo: } \\
\text { capacitación y } \\
\text { compromiso } \\
\text { empleado. }\end{array}$ & $\begin{array}{l}\text { Identifica una relación positiva entre las } \\
\text { prácticas que componen este sistema y la } \\
\text { mejora del desempeño organizativo. }\end{array}$ \\
\hline $\begin{array}{l}\text { Guthrie } \\
\text { (2001) }\end{array}$ & $\begin{array}{l}\text { Prácticas de alta implicación: } \\
\text { - Promoción interna; } \\
\text { - Evaluación basada en el rendimiento; } \\
\text { - Distribución de acciones entre los } \\
\text { empleados; } \\
\text { - Formación intensiva en aptitudes y } \\
\text { competencias; } \\
\text { - Programas de participación de los } \\
\text { empleados; } \\
\text { - Intercambio de información; } \\
\text { - Uso de encuestas de actitud y } \\
\text { - Gestión equipos de trabajo. }\end{array}$ & $\begin{array}{l}\text { Desempeño individual: } \\
\text { retención de los } \\
\text { trabajadores y } \\
\text { productividad. }\end{array}$ & $\begin{array}{l}\text { Existe una relación positiva entre las } \\
\text { prácticas de alta implicación, y la retención } \\
\text { y productividad de los empleados. }\end{array}$ \\
\hline
\end{tabular}




\begin{tabular}{|l|l|l|l|}
\hline Autores & \multicolumn{1}{|c|}{ Variable independiente sistémica } & Variable dependiente & \multicolumn{1}{c|}{ Conclusiones } \\
\hline $\begin{array}{l}\text { Tzaffir } \\
(2006)\end{array}$ & $\begin{array}{l}\text { Prácticas de inversión en el capital } \\
\text { humano: } \\
\text { - Selección selectiva y } \\
\text { Participación de los empleados. }\end{array}$ & $\begin{array}{l}\text { Desempeño } \\
\text { organizativo: } \\
\text { rendimiento } \\
\text { empleados }\end{array}$ & $\begin{array}{l}\text { Sus resultados indican que las empresas } \\
\text { consiguen mayor rendimiento en sus } \\
\text { empleados, gracias a la inversión en } \\
\text { habilidades y conocimientos. Este } \\
\text { mecanismo es fomentado a través de una } \\
\text { selección selectiva y la participación y } \\
\text { cooperación de los empleados. Asimismo, } \\
\text { el estudio destaca el efecto directo sobre el } \\
\text { desempeño de estas dos prácticas. }\end{array}$ \\
\hline
\end{tabular}

Tabla 1. Prácticas destacadas de la literatura en High Performance Work Systems

Adicionalmente, para obtener un patrón homogéneo de prácticas de recursos humanos que incorporarán una preocupación socialmente responsable por el empleado y su entorno, se realizó un examen detallado de las memorias anuales de RSC en las compañías que componen el IBEX-35 (Índice Bursátil Español), dado que éstas compañías se sitúan como empresas referentes en términos de competitividad en España, y a su vez, forman parte de las 100 empresas más responsables, atendiendo al ranking Monitor Empresarial de Reputación Corporativa (MERCO). En concreto, se inspeccionaron 36 memorias (Abengoa, Abertis, Acciona, Acerinox, ACS, Amadeus, Arcelormittal, Banco Popular, Banco Sabadell, Banco Santander, Bankia, Bankinter, BBVA, BME, Caixabank, Dia, EbroFoods, Enagas, Endesa, FCC, Ferrovial, Gamesa, Gas Natural, Grifols, IAG, Iberdrola, Inditex, Indra, Mapfre, Mediaset, OHL, R.E.C., Repsol, Sacyr Valle, Tec.Reunidas y Telefonica) en los apartados de gestión laboral y recursos humanos en dichas compañías, detectando como principal inconveniente la existencia de una gran divergencia en cuanto a sus contenidos. Ante la dificultad de encontrar una propuesta generalizada, y atendiendo a que la mayoría de estas empresas tenían acreditadas sus prácticas de responsabilidad social sobre la base y/o adhesión de diferentes estándares nacionales o internacionales de RSC (Global Compact, Carbon Disclosure, DJS index, FTSE4 Good), se seleccionó un indicador que fuera de aplicación y verificación común para todas ellas.

Con la salvedad de las empresas Bankia y Dia, cuyos informes de RSC 2011 no estaban disponibles para el período analizado, se observó que 34 de las 36 empresas examinadas habían publicado informes sociales o memorias de sostenibilidad verificadas por un auditor independiente común perteneciente a la entidad Global Reporting Initiative. Además, se pudo extraer como resultado de esta revisión que las empresas analizadas incluyen una descripción generalizada de sus políticas y prácticas de recursos humanos dentro de sus memorias de RSC anuales, de acuerdo a los indicadores que propone el Global Reporting Initiative (GRI) (2002, 2006, 2011), y que, por tanto, se puede extraer un patrón genérico de políticas y prácticas de recursos humanos socialmente responsables. En concreto, revisando el apartado dedicado a la definición de los indicadores sociales del GRI, se identificaron seis políticas de gestión de 
recursos humanos (empleo, gestión de las relaciones laborales, seguridad laboral y ocupacional, formación y desarrollo de los trabajadores, diversidad e igualdad de oportunidades, equidad en la compensación y/o remuneración). Estas políticas representan una base coherente para completar la revisión de la literatura, y desarrollar una configuración de políticas de recursos humanos socialmente responsables acorde a las mismos.

De manera complementaría, y atendiendo al estudio de Marimon et al. (2012), que examina cuales son los estándares más implantados a nivel internacional entre las empresas que quieran acreditar o implantar comportamientos de responsabilidad social en sus diferentes áreas de gestión, se realizó un análisis complementario de la norma ISO26000. Según Marimon et al. (2012) tanto el GRI como la ISO26000 son los estándares en materia de RSC más implantados en las empresas de todo el mundo.

La Norma ISO 26000 se basa en un consenso internacional alcanzado entre expertos en materia de RSC, quiénes alientan la aplicación de un conjunto de mejores prácticas en responsabilidad social en todo el mundo. Su correcta aplicación acredita un comportamiento socialmente responsable para las empresas en siete áreas esenciales de la organización: gobernanza, derechos humanos, practicas laborales, medio ambiente, prácticas justas de operación, asuntos de consumidores y participación activa y desarrollo de la comunidad.

Del análisis de contenido de la ISO 26000 en su apartado de gestión laboral, se pueden extraer dos políticas de recursos humanos (condiciones de trabajo y protección social, y comunicación y diálogo social) que complementan a las seis anteriores identificadas en la revisión del GRI. Así, se pudo conformar un abanico de ocho políticas de recursos humanos socialmente responsables tras examinar el contenido de los apartados de gestión social y laboral de los estándares GRI e ISO 26000 (ver Tabla 2).

\begin{tabular}{|c|c|c|}
\hline $\begin{array}{l}\text { Políticas de Gestión de Recursos Humanos } \\
\text { Socialmente Responsables }\end{array}$ & GRI & ISO 26000 \\
\hline Empleo & $\sqrt{ }$ & $\sqrt{ }$ \\
\hline Gestión de las relaciones laborales & $\sqrt{ }$ & $\sqrt{ }$ \\
\hline Seguridad laboral y ocupacional & $\sqrt{ }$ & $\sqrt{ }$ \\
\hline Formación y desarrollo & $\sqrt{ }$ & $\sqrt{ }$ \\
\hline Diversidad e igualdad de oportunidades & $\sqrt{ }$ & $\sqrt{ }$ \\
\hline Equidad en la remuneración & $\sqrt{ }$ & \\
\hline Condiciones de trabajo y protección social & & $\sqrt{ }$ \\
\hline Comunicación y diálogo social & & $\sqrt{ }$ \\
\hline
\end{tabular}

Tabla 2. Consenso de políticas de recursos humanos obtenido a través del análisis de los estándares de responsabilidad social corporativa. 
Tras la revisión de contenido anterior se propusieron ocho políticas específicas de recursos humanos socialmente responsables definidas por cuatro prácticas para cada una. El criterio de elección de las cuatro prácticas tiene carácter exploratorio, y se dirige a generar una primera base teórica para a posteriori, examinar en un panel de expertos, el peso relativo de dichas prácticas.

La escasez de literatura posicionaba al panel de expertos como el método más apropiado para validar desde un punto de vista académico un conjunto de políticas y prácticas de recursos humanos calificadas como socialmente responsables. Para ello, atendiendo a la propuesta de Astigarraga (2005) se definieron cuatro fases que podían ayudar a una mejor implementación del Delphi:

- formulación del problema,

- elección de expertos,

- elaboración y lanzamiento de los cuestionarios y

- desarrollo práctico y explotación de resultados.

En la primera etapa de formulación del problema, se estableció como objetivo encontrar un grado de consenso acerca de los contenidos teóricos de las políticas y prácticas de recursos humanos socialmente responsables, así como el peso relativo de cada una estas prácticas con relación a su importancia para definir a la política que la engloba.

En la segunda fase se determinaron los criterios utilizados para elegir a estos candidatos:

- experiencia académica docente e investigadora reconocida y notable;

- participación activa en congresos, seminarios y talleres nacionales e internacionales;

- poseer publicaciones de impacto en el ámbito de la gestión de recursos humanos; y

- participación como revisor o editor en revistas y congresos científicas en el campo de la GRH tanto a nivel nacional como internacional.

La elección de la muestra de expertos se realizó revisando las páginas Webs de diferentes Universidades y los currículos profesionales de los potenciales participantes. De acuerdo con Astigarraga (2005), obtener una muestra de entre 7 y 30 expertos se considera suficiente para acometer con garantías esta metodología, ya que el éxito de la misma no reside en el número de expertos encuestados, sino en que éstos cuenten con un alto grado de experiencia. Así, se preseleccionaron 25 participantes para llevar a cabo el panel de expertos. 
La tercera etapa consistía en la elaboración y lanzamiento del cuestionario. Para que los expertos pudieran evaluar el contenido de las políticas y prácticas de recursos humanos socialmente responsables se les preguntó acerca de:

- si estaban de acuerdo con su contenido teórico definido;

- si a su juicio, mantendrían la práctica como elemento capaz de definir a la política de recursos humanos socialmente responsable que la engloba; y

- el porcentaje que atribuirían a cada práctica en función de su importancia para definir a la política desde un punto de vista de responsabilidad social (se estableció por defecto un peso relativo del $25 \%$ para cada una de las cuatro prácticas que definían a cada política).

Finalmente, se incluyó para cada política un espacio abierto en el que hacer sugerencias de modificación en cuanto a los contenidos teóricos y el peso relativo de las cuatro prácticas que definían a la política.

Para el envío del cuestionario a los miembros del panel de expertos se eligió la plataforma virtual SurveyMonkey como portal online desde el que coordinar mensajes, avisos, el seguimiento y recepción de las encuestas. En la primera ronda del Delphi se obtuvieron 18 respuestas de un total de 25 académicos seleccionados, lo que supuso una participación del 72\%. Para el análisis de los resultados, se aplicó un criterio que consideró válidas aquellas prácticas de recursos humanos que gozaban de un $80 \%$ o porcentaje mayor de consenso entre los expertos con relación a:

- contenido teórico;

- si esta práctica debía mantenerse o no para definir a la política que la engloba; y

- el peso relativo que el experto atribuiría a la práctica para definir a su política correspondiente.

Por último, se realizó un análisis de contenido para examinar la definición y sugerencias de los expertos sobre cada una de las prácticas, al igual que un apartado de observaciones que se habilitó para ello.

Tras analizar los resultados del primer envío y realizar las correcciones oportunas, se implementó la segunda ronda del panel. En ella, se envió el resultado agregado, con las conclusiones y observaciones de la primera ronda a los participantes, justificando cuales habían sido los criterios usados para realizar las modificaciones. Entre estas correcciones, y a sugerencia de varios expertos, se ofreció una definición para cada una de las diferentes políticas de recursos humanos socialmente responsables para el buen entendimiento de la misma, y de las prácticas que la definen. En la segunda ronda, participaron 17 de los 18 académicos implicados en la primera etapa del Delphi, lo que suponía aproximadamente un 94\% de participación. Estos expertos ayudaron a conformar la definición y pesos relativos para las diferentes prácticas de recursos humanos socialmente responsables. Tomando en consideración el mismo 
porcentaje de consenso (del $80 \%$ o más en cada uno de los contenidos y pesos relativos de las prácticas), se recibieron 17 respuestas a las que se les realizó el análisis de contenido, modificando y redactando algunos ítems de acuerdo con las sugerencias de los expertos.

Finalizada la segunda etapa, se implementó la tercera ronda del Delphi, enviando a los expertos las correcciones realizadas a los ítems, dejando abierta la posibilidad de su retroalimentación vía correo electrónico y/o teléfono. Los resultados de la definición de estas políticas de recursos humanos con una orientación social quedan resumidos en la Tabla 3.

Así, se definieron ocho políticas caracterizadas por incorporar aspectos humanos, éticos, laborales y sociales, encaminadas a obtener objetivos de mejora y bienestar social en las condiciones de trabajo de los empleados:

- atracción y retención de los trabajadores;

- formación y desarrollo continuo;

- gestión de las relaciones laborales;

- comunicación, transparencia y diálogo social;

- diversidad e igualdad de oportunidades;

- remuneración justa y beneficios sociales;

- prevención, seguridad y salud laboral; y

- conciliación de la vida laboral y familiar.

De este modo, se plantea cómo el llevar a cabo políticas que respeten y satisfagan los derechos y expectativas no sólo económicas, sino también éticas, humanas y sociales de los empleados pueden ser eficaces y rentables para la organización. Así, la atracción y retención de los trabajadores, la formación y desarrollo continuo, la gestión de las relaciones laborales, la comunicación, transparencia y diálogo social, la diversidad e igualdad de oportunidades, la remuneración justa y beneficios sociales, la prevención, seguridad y salud laboral y la conciliación de la vida laboral y familiar, pueden suponer un valor añadido y diferencial en el trato y gestión del capital humano para las empresas que conduzca a un mayor desempeño organizativo. 


\begin{tabular}{|l|l|}
\hline $\begin{array}{l}\text { Políticas RRHH socialmente } \\
\text { responsables }\end{array}$ & \multicolumn{1}{c|}{ Definición aceptada por el panel de expertos } \\
\hline $\begin{array}{l}\text { Atracción y retención de los } \\
\text { trabajadores }\end{array}$ & $\begin{array}{l}\text { Conjunto de actividades que tienen por objetivo facilitar los procesos de reclutamiento, } \\
\text { adaptación e integración y retención de los nuevos candidatos, así como de aquellos más } \\
\text { cualificados para la organización. }\end{array}$ \\
\hline $\begin{array}{l}\text { Formación y desarrollo } \\
\text { continuo }\end{array}$ & $\begin{array}{l}\text { Conjunto de actividades que ayuda a que los empleados puedan adquirir los } \\
\text { conocimientos, habilidades y competencias que realmente necesitan para desempeñar de } \\
\text { manera apropiada sus tareas dentro de la empresa. }\end{array}$ \\
\hline $\begin{array}{l}\text { Gestión de las relaciones } \\
\text { laborales }\end{array}$ & $\begin{array}{l}\text { Establecimiento de una serie de actividades que ayuden a la mejora de la relación entre la } \\
\text { empresa y los trabajadores. }\end{array}$ \\
\hline $\begin{array}{l}\text { Comunicación, transparencia y } \\
\text { diálogo social }\end{array}$ & $\begin{array}{l}\text { Conjunto de actividades que facilitan la transmisión, intercambio y retroalimentación de } \\
\text { información entre la empresa y los empleados. }\end{array}$ \\
\hline $\begin{array}{l}\text { Diversidad e igualdad de } \\
\text { oportunidades }\end{array}$ & $\begin{array}{l}\text { Conjunto de acciones que aplican los principios de equidad y no discriminación, así } \\
\text { como fomentan la riqueza y variedad de la fuerza laboral a la hora de gestionar la } \\
\text { plantilla. }\end{array}$ \\
\hline $\begin{array}{l}\text { Remuneración justa y beneficios } \\
\text { sociales }\end{array}$ & $\begin{array}{l}\text { Recompensas económicas y complementos sociales, que reciben los empleados de } \\
\text { manera equitativa por su trabajo realizado. }\end{array}$ \\
\hline $\begin{array}{l}\text { Prevención, seguridad y salud } \\
\text { laboral }\end{array}$ & $\begin{array}{l}\text { Conjunto de actividades que tratan de instaurar un nivel apropiado de bienestar para los } \\
\text { empleados, así como una cultura preventiva que minimice los riesgos, daños físicos y } \\
\text { emocionales derivados del trabajo. }\end{array}$ \\
\hline $\begin{array}{l}\text { Conciliación de la vida laboral y } \\
\text { familiar }\end{array}$ & $\begin{array}{l}\text { Conjunto de acciones destinadas a facilitar un adecuado equilibrio entre la vida } \\
\text { profesional y personal de los empleados, acorde a sus necesidades y las de la empresa. }\end{array}$ \\
\hline
\end{tabular}

Tabla 3. Consenso sobre la definición de las políticas de recursos humanos socialmente responsables

Para medir el impacto de las políticas socialmente responsables se ha utilizado como variable desempeño el capital intelectual (CI), activo que se está posicionando en la literatura como una variable intangible de gran relevancia en la generación de valor y mejora de los resultados organizativos (Andriessen, 2004; Zéghal \& Maaloul, 2010).

\subsection{Importancia estratégica del Capital Intelectual}

El concepto de CI ha sido ampliamente analizado en el ámbito de la gestión empresarial, cobrando mayor relevancia académica a partir de los años noventa con la denominada "economía del conocimiento" (Morris \& Snell, 2011). El amplio espectro de autores que han tratado de conceptualizar este activo intangible, han desarrollado diferentes metodologías que ayudan a su identificación, medición y evaluación, con soporte en enfoques como la teoría de recursos y capacidades, la perspectiva de creación del conocimiento o la propia teoría del capital intelectual (Kang \& Snell, 2009).

De los trabajos examinados hasta la fecha puede detraerse que el CI está constituido por una combinación de variables intangibles (conocimientos, experiencias, destrezas información, etc.), que poseen un valor diferencial capaz de generar una ventaja diferencial para la empresa en el mercado, ya que como advierten Nahapiet y Ghosal (1998) o Alama-Salazar (2009) entre otros, cumple con las cuatro características establecidas por Barney (1991) para que un recursos sea capaz de ello: 
- duradero;

- insustituible;

- intransferible; e

- inimitable.

Este hecho, ha consagrado al CI como un activo determinante para la generación de valor para las compañías.

Considerando que nuestro objetivo reside en explicar el efecto de una configuración de políticas de recursos humanos socialmente responsable sobre los resultados y el proceso de generación de valor para la empresa, se tomará como base para examinar este propósito el trabajo de Youndt y Snell (2004). Estos autores plantean la existencia de configuraciones ideales de prácticas de recursos humanos que no inciden exclusivamente de manera directa sobre el desempeño organizativo, sino que afectan a la generación de un mayor valor organizativo a través del capital intelectual. Siguiendo su propuesta, el CI puede clasificarse en tres variables principales: capital humano, social y organizacional.

\subsection{Hipótesis de Investigación}

Aclarada la importancia de esta variable intangible en la generación de valor para la empresa, el próximo paso es analizar de manera desagregada el vínculo entre la configuración socialmente responsable propuesta sobre el capital humano, social y organizacional de la empresa.

Teniendo en cuenta los potenciales efectos de cada una de las políticas socialmente responsable de recursos humanos sobre el proceso de generación de valor en la empresa, y por tanto sobre el capital intelectual (Surroca, Tribó \& Waddock, 2010), se pretende poner de manifiesto cómo la implementación de una orientación ética y social en la gestión de recursos humanos también puede ayudar a desarrollar los niveles de capital humano, social y organizacional de la empresa. Para ello, se proponen las siguientes hipótesis y sub-hipótesis:

Hipótesis 1: Una orientación socialmente responsable de las políticas y prácticas de recursos humanos permite generar un mayor capital intelectual en la empresa.

Hipótesis 1.1: Una orientación socialmente responsable de la permite generar un mayor capital bumano en la empresa.

Hipótesis 1.2: Una orientación socialmente responsable de la politica de formación permite generar un mayor capital social en la empresa. 
Hipótesis 1.3: Una orientación socialmente responsable de la política de comunicación permite generar un mayor capital organizacional.

\section{Metodología}

\subsection{Diseño muestral}

Para identificar la población de empresas a las cuales se dirigiría la investigación se acudió a SABI (Sistema de Análisis de Balances Ibéricos). SABI es una base de datos perteneciente a Bureau van Dijk Electronic Publishing que contiene información detallada de aproximadamente 1.250.000 empresas españolas y 400.000 portuguesas. Esta base de datos permite hacer búsquedas mediante criterios o filtros específicos, entre los que se encuentran los de interés para este estudio. Se debe puntualizar que el acceso a esta base de datos se realizó a través de la Licencia de la Universidad de Cádiz. Entre los criterios de búsqueda utilizados se seleccionaron cuatro concretos:

- empresas con domicilio social en España;

- empresas activas;

- empresas de gran tamaño (según la recomendación de la Comisión Europea de Dirección General de Empresa e Industria Diario Oficial L 07 de 30.4.1996, se considera empresa de gran tamaño aquella que posee un número de trabajadores mayor a 250), y

- empresas cuyos estados financieros estuvieran actualizados a fecha 31 de diciembre de 2011.

Este filtro determinó un tamaño poblacional total de 315 empresas. La decisión de llevar a cabo el estudio en grandes empresas españolas tuvo como propósito conocer el panorama de responsabilidad social existente en el ámbito de la gestión de recursos humanos en España. Siguiendo las recomendaciones de Pérez-López (2009) y Morales-Vallejo (2011), quienes advierten de la necesidad de aplicar leyes de tipo estadístico para conocer con exactitud el tamaño mínimo muestral que garantice la condición de representatividad, se aplicó la siguiente ecuación matemática(1):

$$
\mathrm{n}=\left(\mathrm{p}^{*} \mathrm{q}^{*} \mathrm{~N}\right) /\left[(\mathrm{N}-1)(\mathrm{e} / \mathrm{z})^{2}+\mathrm{p} * \mathrm{q}\right]
$$

- $\quad \mathrm{p}^{*} \mathrm{q}=$ Varianza de la población $\left(\sigma^{2}\right)$

- $\quad \mathrm{N}=$ Población total;

- $\mathrm{e}=$ Error de la muestra;

- $\quad z=$ Nivel de confianza; 
Así, asumiendo un margen de error del 10\% y un nivel de confianza del 95\%, sería preciso obtener un tamaño muestral mínimo de 74 observaciones para garantizar la representatividad de esta investigación. A principios de septiembre de 2012, se procedió a contactar con los directivos de recursos humanos de las sedes centrales de las empresas elegidas. El responsable de recursos humanos se identificó como la persona más apropiada para contestar el cuestionario dado su grado de conocimiento y comprensión del diseño e implantación de las políticas y prácticas de recursos humanos en la organización. Para asegurar la fluidez de las respuestas, se utilizó el software SurveyMonkey para el envío de los cuestionarios. De este modo, a fecha 27 de diciembre de 2012, se obtuvieron un total de 85 observaciones de las 315 empresas con las que durante este periodo de tiempo había llegado a contactarse.

Los resultados alcanzados suponían una participación, aproximada, de un 27\%, asumiendo un margen de error del $9.09 \%$ y un nivel de confianza del $95 \%$ atendiendo a la formulación matemática establecida previamente.

\subsection{Definición y medición de las variables del modelo}

Para la definición y medición de las variables a continuación se concreta el procedimiento utilizado.

\subsubsection{Políticas y prácticas de recursos humanos socialmente responsables}

Ante la escasez de literatura existente, para proceder a la definición de las políticas y prácticas de recursos humanos socialmente responsable se acudió a tres vías complementarias:

- análisis de la literatura especializada en materia de responsabilidad social y gestión de recursos humanos;

- análisis basado en la descripción objetiva de los apartados de gestión social y laboral en las memorias de responsabilidad social de las empresas españolas del IBEX-35, al igual que los estándares internacionales en materia de RSC (GRI e ISO26000); y,

- el diseño de un panel de expertos, que permitió a través de una metodología Delphi, desarrollada en tres rondas, y dirigida a 25 académicos procedentes de diferentes Universidades españolas, obtener un consenso final de al menos un $80 \%$ de sus valoraciones en lo que a tres aspectos se refiere:

- contenido teórico de la política y sus prácticas; 
- si a su juicio, mantendrían la práctica como elemento capaz de definir a la política de recursos humanos socialmente responsable que la engloba; y

- el porcentaje que atribuirían a cada práctica en función de su importancia para definir a la política desde un punto de vista de responsabilidad social (se estableció por defecto un peso relativo del 25\% para cada una de las cuatro prácticas que definían a cada política).

Se registró una participación de un total de 17 expertos. Por medio de estos análisis, se obtuvieron 32 prácticas medidas en escala de Likert de 1 a 7 donde "1" representaba la mínima implantación de la práctica y "7” la máxima implantación de la misma que conformaban las ocho políticas de recursos humanos socialmente responsables (atracción y retención de los trabajadores, formación y desarrollo continuo, gestión de las relaciones laborales, comunicación, transparencia y diálogo social, diversidad e igualdad de oportunidades, remuneración justa y beneficios sociales, prevención, seguridad y salud laboral y conciliación de la vida laboral y familiar) incluidas en el modelo de investigación. Hay que subrayar, que el intervalo de "1" a "7" fue utilizado considerando que el uso de nuevas variables no contrastadas, previamente, en la literatura, permitiría obtener mayor variabilidad de respuesta que el del estándar de medición de " 1 ” a "5" definido en la mayoría de trabajos académicos.

\subsubsection{Capital intelectual}

Atendiendo a los ítems de Youndt y Snell (2004), el capital intelectual ha sido definido, a través de las variables: capital humano, social y organizacional.

- El capital humano pretende determinar los conocimientos, habilidades y experiencias de los empleados. Siguiendo a estos autores ha sido medido a través de cinco ítems desarrollados en la Tabla 4 valorados en una escala de Likert de "1" (totalmente en desacuerdo) a "7" (totalmente de acuerdo).

- El capital social trata de delimitar el valor de las relaciones e intercambios que se generan entre los empleados de la empresa, gracias al desarrollo de atributos como la cohesión, la confianza y la reciprocidad. En este sentido, al igual que realizan Youndt y Snell (2004) se han usado cinco items medidos en escala de Likert de "1" (totalmente en desacuerdo) a "7" (totalmente de acuerdo), adjuntos en la Tabla 4.

- El capital organizacional representa el conocimiento institucionalizado y codificado de la empresa en bases de datos, patentes, rutinas, manuales y la propia estructura de la empresa. Este concepto ha sido medido a través de cuatro ítems (Tabla 4), en una escala de Likert de "1" (totalmente en desacuerdo) a "7" (totalmente de acuerdo) para determinar este activo intangible. 
Por último, se definieron una serie de variables de control con la intención de medir los posibles efectos que estas terceras variables pudieran tener sobre las relaciones descritas en el modelo de investigación.

\subsubsection{Variables de control}

Para esta investigación se consideraron tres variables de control principales, que de acuerdo con la revisión de la literatura, podían afectar de manera significativa a las relaciones establecidas entre las variables implicadas en el estudio. Estas son el ámbito de actuación de la empresa, el sector de actividad y el tamaño de la organización.

En lo que se refiere al ámbito de actuación de la empresa fue incluida en el estudio porque, como advierte Urgal, Quintás and Arévalo-Tomé (2011), puede permitir delimitar el espacio geográfico de intercambio de bienes y servicios de la compañía, aspecto que puede afectar a los recursos de la empresa y, más concretamente, a la gestión del capital humano. Teóricamente, trabajos como el de Brewster, Mayrhofer and Morley (2004) explican que la gestión de los recursos humanos reviste mayor complejidad en compañías que operan a nivel europeo o internacional en contrapartida con aquellas empresas que realizan sus operaciones a nivel nacional y/o local, dado que las primeras deben afrontar una serie de factores culturales, socioeconómicos, políticos y legales sometidas a mayor regulación por entidades supranacionales, a diferencia de aquellas que operan en un ámbito nacional. En este mismo sentido, estudios como los de Urgal et al. (2011) ponen de manifiesto que la orientación que pueden adoptar las empresas en sus prácticas de gestión variará circunstancialmente en función del ámbito o alcance geográfico en el que desempeñe su actividad, siendo preciso controlar estos efectos. Bajo estos argumentos, esta investigación incluye la variable ámbito de actuación de la empresa con la intención de controlar los efectos qué desarrollar políticas y prácticas de recursos humanos socialmente responsables puede tener sobre el desempeño organizativo en función del contexto nacional o internacional en el que operan. Su definición ha sido realizada a través de una variable categórica medida con cuatro alternativas de respuesta (1= ámbito local; 2= ámbito nacional; 3= ámbito europeo; 4=ámbito internacional), siguiendo la escala propuesta por Urgal et al. (2011). Se decidió incluir una categoría adicional, "ámbito europeo", siguiendo las recomendaciones teóricas de Brewster et al. (2004), quién subraya las diferencias existentes entre el ámbito europeo e internacional, y cómo este contexto puede afectar a la función de GRH.

La segunda de las variables de control usadas en el estudio ha sido el sector de actividad, remarcada por diversos autores en la literatura como condicionante tanto en el análisis de la función de GRH sobre los resultados de la empresa (Youndt \& Snell, 2004). Para definirla, se consideró la actividad económica 
principal de cada empresa atendiendo al CNAE 2009 desarrollado en los años de referencia de la investigación (2010 y 2011). Su medición se ha realizado a través de las categorías: "1" correspondiente a empresas pertenecientes al sector primario; "2" para aquellas del sector secundario; y " 3 " para las empresas cuya actividad económica pertenece al sector terciario como justifican Mittal, Sinha and Singh (2008) y Urgal et al. (2011) entre otros.

Por último, se ha considerado como tercera variable control el tamaño empresarial, entendida como el número de empleados totales que posee la empresa. Siguiendo las recomendaciones de Youndt y Snell (2004) y Huselid (1995). No se decidió categorizar esta variable con la intención de controlar el efecto que pudiera presentar el número de empleados sobre los resultados organizativos.

\section{Análisis de resultados}

Antes de proceder al contraste de las hipótesis se realizaron los análisis descriptivos, fiabilidad y validez de las variables del modelo.

\begin{tabular}{|c|c|c|c|c|c|c|}
\hline \multicolumn{2}{|c|}{$\begin{array}{c}\text { Prácticas de recursos } \\
\text { humanos }\end{array}$} & \multirow[b]{2}{*}{\begin{tabular}{l}
\multicolumn{1}{c}{ Descripción ítem } \\
Las pruebas utilizadas en los procesos de \\
reclutamiento y selección -búsqueda de \\
aspirantes, entrevistas, etc.- se inspiran en la \\
adecuación del candidato a: la cultura de la \\
empresa, la formación, las posibilidades de \\
crecimiento y promoción dentro de la \\
organización
\end{tabular}} & \multirow{2}{*}{\begin{tabular}{r|} 
Media \\
5.54
\end{tabular}} & \multirow{2}{*}{\begin{tabular}{|c|} 
Desv. \\
Típica \\
\\
\\
\\
1.46
\end{tabular}} & \multirow{2}{*}{\begin{tabular}{r|} 
Mínimo \\
\\
1
\end{tabular}} & \multirow{2}{*}{$\begin{array}{r}\text { Máximo } \\
\\
7\end{array}$} \\
\hline \multirow{4}{*}{$\begin{array}{l}\text { Prácticas de } \\
\text { atracción y } \\
\text { retención de los } \\
\text { trabajadores }\end{array}$} & Práctica 4.1 & & & & & \\
\hline & Práctica 4.2 & $\begin{array}{l}\text { Utiliza procesos específicos para la adaptación e } \\
\text { integración de los nuevos candidatos en la } \\
\text { empresa como la entrega de un manual de } \\
\text { acogida, la formación sobre la cultura de la } \\
\text { empresa, etc. }\end{array}$ & 5.93 & 1.45 & 1 & 7 \\
\hline & Práctica 4.3 & $\begin{array}{l}\text { Establece mecanismos transparentes de } \\
\text { promoción interna, llevando a cabo actividades } \\
\text { como la comunicación de futuras vacantes y } \\
\text { planes de carrera para hacerlos accesibles al } \\
\text { conocimiento de todos los empleados }\end{array}$ & 5.56 & 1.38 & 1 & 7 \\
\hline & Práctica 4.4 & $\begin{array}{l}\text { Fomenta la retención de los trabajadores más } \\
\text { capacitados y con mayor experiencia a través de } \\
\text { mecanismos de motivación como la } \\
\text { implementación de un programa de incentivos } \\
\text { por cumplimiento de metas, premios por actitud } \\
\text { colaborada, etc. }\end{array}$ & 5.15 & 1.74 & 1 & 7 \\
\hline
\end{tabular}




\begin{tabular}{|c|c|c|c|c|c|c|}
\hline \multicolumn{2}{|c|}{$\begin{array}{c}\text { Prácticas de recursos } \\
\text { humanos }\end{array}$} & \multirow{2}{*}{$\begin{array}{l}\text { Descripción ítem } \\
\text { Crea un entorno de trabajo que estimula el } \\
\text { aprendizaje, autonomía y sentimiento de } \\
\text { aspiración y mejora continua a través de dinámicas } \\
\text { de grupo y entrevistas con los empleados }\end{array}$} & \multirow{2}{*}{\begin{tabular}{r|} 
Media \\
4.89
\end{tabular}} & \multirow{2}{*}{\begin{tabular}{|r|}
$\begin{array}{c}\text { Desv. } \\
\text { Típica }\end{array}$ \\
1.35 \\
\end{tabular}} & \multirow{2}{*}{\begin{tabular}{r|} 
Mínimo \\
1
\end{tabular}} & \multirow{2}{*}{$\begin{array}{r}\text { Máximo } \\
7\end{array}$} \\
\hline \multirow{4}{*}{$\begin{array}{l}\text { Prácticas de } \\
\text { formación y } \\
\text { desarrollo } \\
\text { continuo }\end{array}$} & Práctica 5.1 & & & & & \\
\hline & Práctica 5.2 & $\begin{array}{l}\text { Detecta de manera periódica las necesidades de } \\
\text { formación de la plantilla, estableciendo } \\
\text { metodologías presenciales de aprendizaje - } \\
\text { seminarios, cursos, etc.- y no presenciales -tele- } \\
\text { formación vía Intranet, formación a distancia, } \\
\text { etc.- }\end{array}$ & 5.82 & 1.32 & 2 & 7 \\
\hline & Práctica 5.3 & $\begin{array}{l}\text { Realiza evaluaciones regulares del desempeño de } \\
\text { los empleados con el fin de mejorar su desarrollo } \\
\text { profesional y enriquecimiento en sus puestos de } \\
\text { trabajo }\end{array}$ & 5.07 & 1.66 & 1 & 7 \\
\hline & Práctica 5.4 & $\begin{array}{l}\text { Fomenta la interacción y el intercambio de } \\
\text { conocimientos entre los empleados a través de } \\
\text { aspectos como la rotación interna, reuniones de } \\
\text { grupo, tormenta de ideas - brainstornming-, etc. }\end{array}$ & 4.87 & 1.51 & 1 & 7 \\
\hline \multirow{4}{*}{$\begin{array}{l}\text { Prácticas de } \\
\text { gestión de las } \\
\text { relaciones } \\
\text { laborales }\end{array}$} & Práctica 6.1 & $\begin{array}{l}\text { Se preocupa por lograr un clima de trabajo } \\
\text { cómodo para los empleados, que respete su } \\
\text { dignidad y ayude a satisfacer sus necesidades y } \\
\text { expectativas personales de carácter éticas, sociales } \\
\text { y laborales }\end{array}$ & 5.86 & 0.96 & 3 & 7 \\
\hline & Práctica 6.2 & $\begin{array}{l}\text { Facilita la interacción de los trabajadores con sus } \\
\text { representantes para favorecer el diálogo y la } \\
\text { gestión del conflicto con la empresa }\end{array}$ & 5.39 & 1.31 & 1 & 7 \\
\hline & Práctica 6.3 & $\begin{array}{l}\text { Establece reuniones periódicas así como otros } \\
\text { mecanismos de interacción que faciliten el } \\
\text { establecimiento de una relación de confianza, } \\
\text { honestidad, reciprocidad y compromiso entre los } \\
\text { mandos y subordinados }\end{array}$ & 5.87 & 1.14 & 2 & 7 \\
\hline & Práctica 6.4 & $\begin{array}{l}\text { Comunica y explica a los empleados con mayor } \\
\text { antelación al período mínimo legal, aquellos } \\
\text { cambios y notificaciones que pueden afectar su } \\
\text { relación contractual con la empresa }\end{array}$ & 5.74 & 1.27 & 2 & 7 \\
\hline \multirow{4}{*}{$\begin{array}{l}\text { Prácticas de } \\
\text { comunicación, } \\
\text { transparencia y } \\
\text { diálogo social }\end{array}$} & Práctica 7.1 & $\begin{array}{l}\text { Establece mecanismos formales e informales de } \\
\text { comunicación entre sus empleados como } \\
\text { reuniones de grupo, entrevistas personales, } \\
\text { difusión de boletines informativos, uso de redes } \\
\text { sociales, etc. }\end{array}$ & 5.79 & 1.19 & 2 & 7 \\
\hline & Práctica 7.2 & $\begin{array}{l}\text { La comunicación con los empleados es } \\
\text { transparente, suministrando la información } \\
\text { relacionada con las acciones y resultados de la } \\
\text { empresa en materia económica, social y } \\
\text { medioambiental }\end{array}$ & 5.61 & 1.17 & 2 & 7 \\
\hline & Práctica 7.3 & $\begin{array}{l}\text { Facilita el diálogo social entre los empleados, } \\
\text { creando un entorno comunicativo libre en el que } \\
\text { estos pueden conocerse, confiar mutuamente, } \\
\text { acostumbrarse a compartir información y } \\
\text { consultarse con independencia de su estatus o } \\
\text { categoría profesional en la empresa. }\end{array}$ & 5.69 & 1.09 & 2 & 7 \\
\hline & Práctica 7.4 & $\begin{array}{l}\text { Fomenta la participación y el intercambio de ideas } \\
\text { entre los trabajadores tanto a nivel horizontal y } \\
\text { vertical, utilizando herramientas como los círculos } \\
\text { de calidad, un sistema de sugerencias, etc. }\end{array}$ & 5.15 & 1.35 & 1 & 7 \\
\hline
\end{tabular}




\begin{tabular}{|c|c|c|c|c|c|c|}
\hline \multicolumn{2}{|c|}{$\begin{array}{c}\text { Prácticas de recursos } \\
\text { humanos }\end{array}$} & \multirow{2}{*}{$\begin{array}{l}\text { Descripción ítem } \\
\text { Garantiza la aplicación de los principios de } \\
\text { diversidad e igualdad de oportunidades en todas } \\
\text { las políticas, prácticas y procesos de gestión de } \\
\text { recursos humanos de la empresa, ayudando a la } \\
\text { creación de planes de igualdad para la empresa }\end{array}$} & \multirow{2}{*}{\begin{tabular}{r|} 
Media \\
5.94
\end{tabular}} & \multirow{2}{*}{\begin{tabular}{|r|}
$\begin{array}{c}\text { Desv. } \\
\text { Típica }\end{array}$ \\
\\
\\
1.33 \\
\end{tabular}} & \multirow{2}{*}{\begin{tabular}{|r|} 
Mínimo \\
1 \\
\end{tabular}} & \multirow{2}{*}{ Máximo } \\
\hline \multirow{4}{*}{$\begin{array}{l}\text { Prácticas de } \\
\text { diversidad e } \\
\text { igualdad de } \\
\text { oportunidades }\end{array}$} & Práctica 8.1 & & & & & \\
\hline & Práctica 8.2 & $\begin{array}{l}\text { Detecta necesidades de formación en sus } \\
\text { empleados en materia de diversidad e igualdad de } \\
\text { oportunidades a través de evaluaciones periódicas } \\
\text { de sus conocimientos con el objetivo de solventar } \\
\text { estas carencias }\end{array}$ & 4.67 & 1.66 & 1 & 7 \\
\hline & Práctica 8.3 & $\begin{array}{l}\text { Potencia los principios de diversidad e igualdad de } \\
\text { oportunidades como criterio imprescindible para } \\
\text { alcanzar la excelencia en la composición, } \\
\text { estructuración y gestión de su plantilla }\end{array}$ & 5.28 & 1.67 & 1 & 7 \\
\hline & Práctica 8.4 & $\begin{array}{l}\text { Crea equipos de trabajo diversos con el propósito } \\
\text { de desarrollar ideas, opiniones de grupo, flujos de } \\
\text { trabajo y un mayor nivel de creatividad en la } \\
\text { plantilla }\end{array}$ & 4.71 & 1.96 & 1 & 7 \\
\hline \multirow{4}{*}{$\begin{array}{l}\text { Prácticas de } \\
\text { remuneración } \\
\text { justa y } \\
\text { beneficios } \\
\text { sociales }\end{array}$} & Práctica 9.1 & $\begin{array}{l}\text { Garantiza los principios de justicia, transparencia } \\
\text { y equidad tanto a nivel interna como externa a la } \\
\text { hora de remunerar el trabajo realizado por los } \\
\text { empleados }\end{array}$ & 5.91 & 1.27 & 1 & 7 \\
\hline & Práctica 9.2 & $\begin{array}{l}\text { Remunera a los empleados tanto en función de las } \\
\text { competencias que posean como de su desempeño } \\
\text { periódico. }\end{array}$ & 5.48 & 1.52 & 1 & 7 \\
\hline & Práctica 9.3 & $\begin{array}{l}\text { Proporciona beneficios sociales a los empleados } \\
\text { como mecanismo de retención y estímulo, que } \\
\text { complementan a su remuneración económica: } \\
\text { becas de estudio para familiares, seguros de vida, } \\
\text { ayudas a guardería, plan de jubilación, } \\
\text { participación en campañas sociales u ONG, etc. }\end{array}$ & 5.38 & 1.85 & 1 & 7 \\
\hline & Práctica 9.4 & $\begin{array}{l}\text { Proporciona medios y recursos que representan } \\
\text { un ahorro de costes directos a los trabajadores - } \\
\text { alquiler de vivienda, vehículo propio, etc.- así } \\
\text { como una mejora de sus condiciones laborales } \\
\text {-asistencia social, familiar, etc. }\end{array}$ & 4.80 & 1.85 & 1 & 7 \\
\hline \multirow{4}{*}{$\begin{array}{l}\text { Prácticas de } \\
\text { prevención, } \\
\text { seguridad y } \\
\text { salud laboral }\end{array}$} & $\begin{array}{c}\text { Práctica } \\
10.1\end{array}$ & $\begin{array}{l}\text { Realiza programas y acciones formativas } \\
\text { destinadas a mejorar la prevención, seguridad y } \\
\text { salud laboral de los empleados que van más allá de } \\
\text { los requerimientos legales establecidos }\end{array}$ & 6.07 & 1.11 & 2 & 7 \\
\hline & $\begin{array}{c}\text { Práctica } \\
10.2\end{array}$ & $\begin{array}{l}\text { Asigna tareas de seguimiento y control a los } \\
\text { empleados adicionales a las legalmente } \\
\text { establecidas en materia de seguridad y salud } \\
\text { laboral a fin de instaurar una cultura preocupada } \\
\text { por la prevención, su bienestar físico y emocional } \\
\text { en la empresa }\end{array}$ & 5.71 & 1.21 & 2 & 7 \\
\hline & $\begin{array}{c}\text { Práctica } \\
10.3\end{array}$ & $\begin{array}{l}\text { Acredita un nivel apropiado de seguridad y salud } \\
\text { laboral para los empleados de la empresa a través } \\
\text { de estándares y certificaciones como las OSHAS, } \\
\text { ISOS, etc. }\end{array}$ & 5.67 & 1.78 & 1 & 7 \\
\hline & $\begin{array}{c}\text { Práctica } \\
10.4\end{array}$ & $\begin{array}{l}\text { Minimiza los riesgos físicos y emocionales } \\
\text { derivados del trabajo para los empleados y sus } \\
\text { familias como son el absentismo, estrés, } \\
\text { enfermedades profesionales, accidentes en el } \\
\text { trabajo, etc. }\end{array}$ & 5.67 & 1.20 & 2 & 7 \\
\hline
\end{tabular}




\begin{tabular}{|c|c|c|c|c|c|c|}
\hline \multicolumn{2}{|c|}{$\begin{array}{l}\text { Prácticas de recursos } \\
\text { humanos }\end{array}$} & Descripción ítem & Media & $\begin{array}{l}\text { Desv. } \\
\text { Típica }\end{array}$ & Mínimo & Máximo \\
\hline \multirow{4}{*}{$\begin{array}{l}\text { Prácticas de } \\
\text { conciliación de } \\
\text { la vida laboral y } \\
\text { familiar }\end{array}$} & $\begin{array}{l}\text { Práctica } \\
11.1\end{array}$ & $\begin{array}{l}\text { Facilita la existencia de un equilibrio adecuado } \\
\text { entre la vida laboral y familiar de los empleados }\end{array}$ & 5.60 & 1.43 & 1 & 7 \\
\hline & $\begin{array}{l}\text { Práctica } \\
11.2\end{array}$ & $\begin{array}{l}\text { Facilita modificaciones en la jornada laboral y } \\
\text { turnos de trabajo de los empleados en función de } \\
\text { sus necesidades y las de la empresa }\end{array}$ & 5.74 & 1.51 & 1 & 7 \\
\hline & $\begin{array}{l}\text { Práctica } \\
11.3\end{array}$ & $\begin{array}{l}\text { Otorga flexibilidad en la concesión de permisos } \\
\text { de paternidad y maternidad, periodos de lactancia } \\
\text { y excedencias, en función de las necesidades de } \\
\text { los empleados y las de la empresa }\end{array}$ & 6.28 & 1.33 & 1 & 7 \\
\hline & $\begin{array}{l}\text { Práctica } \\
11.4\end{array}$ & $\begin{array}{l}\text { Facilita el traslado de los empleados a otros } \\
\text { centros de trabajo }\end{array}$ & 4.79 & 2.08 & 1 & 7 \\
\hline \multirow{5}{*}{ Capital humano } & CH 1 & Nuestros empleados están altamente cualificados & 5.07 & 1.27 & 1 & 7 \\
\hline & $\mathrm{CH} 2$ & $\begin{array}{l}\text { Nuestros empleados están considerados } \\
\text { ampliamente como los mejores del sector }\end{array}$ & 4.80 & 1.48 & 1 & 7 \\
\hline & CH 3 & Nuestros empleados son creativos y brillantes & 4.78 & 1.19 & 2 & 7 \\
\hline & $\mathrm{CH} 4$ & $\begin{array}{l}\text { Nuestros empleados son expertos en sus } \\
\text { particulares puestos de trabajo y en el desempeño } \\
\text { de sus tareas }\end{array}$ & 5.64 & 1.19 & 3 & 7 \\
\hline & CH 5 & $\begin{array}{l}\text { Nuestros empleados desarrollan nuevas ideas y } \\
\text { conocimiento }\end{array}$ & 5.09 & 1.36 & 2 & 7 \\
\hline \multirow{5}{*}{ Capital social } & CS 1 & $\begin{array}{l}\text { Nuestros empleados están preparados para } \\
\text { colaborar entre ellos, diagnosticar y resolver } \\
\text { problemas }\end{array}$ & 5.08 & 1.54 & 1 & 7 \\
\hline & $\operatorname{CS} 2$ & $\begin{array}{l}\text { Nuestros empleados comparten la información y } \\
\text { aprenden los unos de los otros }\end{array}$ & 5.01 & 1.52 & 1 & 7 \\
\hline & CS 3 & $\begin{array}{l}\text { Nuestros empleados interactúan e intercambian } \\
\text { ideas con personas de diferentes áreas de la } \\
\text { empresa }\end{array}$ & 4.94 & 1.56 & 1 & 7 \\
\hline & $\operatorname{CS} 4$ & $\begin{array}{l}\text { Nuestros empleados se asocian con clientes, } \\
\text { proveedores, aliados, etc. para desarrollar } \\
\text { soluciones que favorezcan a los intereses de la } \\
\text { empresa }\end{array}$ & 4.66 & 1.74 & 1 & 7 \\
\hline & CS 5 & $\begin{array}{l}\text { Nuestros empleados aplican los conocimientos de } \\
\text { un área de la empresa a los problemas y } \\
\text { oportunidades que surgen en otro }\end{array}$ & 4.60 & 1.68 & 1 & 7 \\
\hline \multirow{4}{*}{$\begin{array}{l}\text { Capital } \\
\text { organizacional }\end{array}$} & CO 1 & $\begin{array}{l}\text { Nuestros empleados usan patentes y licencias } \\
\text { como una forma de almacenar conocimiento }\end{array}$ & 2.81 & 1.72 & 1 & 7 \\
\hline & CO 2 & $\begin{array}{l}\text { Gran parte del conocimiento organizacional está } \\
\text { almacenado en manuales, bases de datos, etc. }\end{array}$ & 4.69 & 1.48 & 1 & 7 \\
\hline & CO 3 & $\begin{array}{l}\text { Nuestra cultura organizativa contiene ideas } \\
\text { valiosas, formas de hacer negocios, etc. }\end{array}$ & 5.06 & 1.61 & 1 & 7 \\
\hline & CO 4 & $\begin{array}{l}\text { Nuestra organización tiene integrado gran parte } \\
\text { de su conocimiento e información en estructuras, } \\
\text { sistemas y procesos. }\end{array}$ & 5.32 & 1.52 & 1 & 7 \\
\hline \multicolumn{2}{|c|}{ Tamaño organizativo } & Número de empleados totales & 736.93 & 756.60 & 251 & 4,404 \\
\hline
\end{tabular}

Tabla 4. Estadísticos descriptivos de las variables $(n=85)$

Como puede observarse en la Tabla 4 con respecto a las puntuaciones medias obtenidas para las diferentes prácticas de recursos humanos socialmente responsable, se aprecian unos valores altos, iguales o superiores a la media, donde destacan los casos de las prácticas 7.1 y 8.3 con puntuaciones de 6.07 y 6.28 respectivamente. Estos valores implican que las prácticas están implantadas en gran medida 
por las empresas de la muestra, y que por tanto llevan a cabo comportamientos socialmente responsables en lo que a la gestión de sus recursos humanos se refiere.

Con respecto a las variables que conforman el capital intelectual los datos obtenidos reflejan un alto grado de conocimientos, habilidades y experiencias en sus empleados $(\mathrm{CH})$, la disposición de una amplia red de relaciones, en las que la se fomenta la confianza y reciprocidad entre sus miembros (CS) y además, la posesión de un conocimiento institucionalizado y generalizado en bases de datos, rutinas y patentes. No obstante, se ha de destacar el valor obtenido (2.81) en el ítem CO1 que refleja como las empresas de la muestra utilizan de manera escasa patentes y licencias. Este resultado no ha causado sorpresa pues, según se pudo comprobar en el pretest, fue uno de los aspectos que presentó una menor valoración por parte de los directivos de recursos humanos por la poca implantación y uso de patentes. Dado que este ítem forma parte de la variable capital organizacional original propuesta por Youndt y Snell, y que presentó buena consistencia como contempla Alama-Salazar (2009), en una revisión de estos trabajos, decidió conservarse sin alteraciones. En lo que se refiere a las políticas de recursos humanos socialmente responsable medidas a través de las 32 prácticas, la Tabla 5 muestra indicadores aceptables del alfa de Cronbach (entre 0.7 y 0.9 ) para todas las políticas confirmando la homogeneidad de sus ítems. En lo referente a las variables capital humano, social y organizacional, el alfa de Cronbach determinó con valores comprendidos entre 0.8 y 0.9, que los ítems de Youndt y Snell (2004) eran fiables para la muestra de 85 observaciones.

Por otra parte, se contrastan los resultados obtenidos en esta investigación con los de los autores originales, reportando que la traducción de los ítems se ha mantenido, asegurando una consistencia interna similar, dado que Youndt y Snell (2004), reportan indicadores de Cronbach para las variables capital humano (0.81), capital social (0.88) y capital organizacional (0.62), aporta valores parecidos, mejorando sensiblemente este indicador para el caso del capital organizacional.

\begin{tabular}{|l|r|}
\hline \multicolumn{1}{|c|}{ Variable } & Alfa de Cronbach \\
\hline Política 1: Atracción y retención de los trabajadores & $\alpha=0.78$ \\
\hline Política 2: Formación y desarrollo continuo & $\alpha=0.87$ \\
\hline Política 3: Gestión de las relaciones laborales & $\alpha=0.79$ \\
\hline Política 4: Comunicación, transparencia y diálogo social & $\alpha=0.79$ \\
\hline Política 5: Diversidad e igualdad de oportunidades & $\alpha=0.85$ \\
\hline Política 6: Remuneración justa y beneficios sociales & $\alpha=0.89$ \\
\hline Política 7: Prevención, seguridad y salud laboral & $\alpha=0.85$ \\
\hline Política 8: Conciliación de la vida laboral y familiar & $\alpha=0.85$ \\
\hline Capital Humano & $\alpha=0.90$ \\
\hline Capital Social & $\alpha=0.90$ \\
\hline Capital Organizacional & $\alpha=0.80$ \\
\hline
\end{tabular}

Tabla 5. Prueba del alfa de Cronbach para las variables del modelo 
Examinada la fiabilidad a través del Alpha de Cronbach, se procedió al estudio de validez de constructo a través del análisis factorial, una de las técnicas estadísticas que puede permitir medir con mayor precisión este aspecto.

\begin{tabular}{|c|c|c|c|c|c|c|c|}
\hline \multirow[t]{2}{*}{ Prácticas examinadas } & \multicolumn{7}{|c|}{ Componente } \\
\hline & 1 & 2 & 3 & 4 & 5 & 6 & 7 \\
\hline PR11_1 & .857 & .106 & & .238 & & & .159 \\
\hline PR11_2 & .833 & .113 & & .100 & .119 & & .244 \\
\hline PR11_3 & .777 & .162 & .269 & .277 & .127 & & .166 \\
\hline PR9_2 & .584 & & .358 & & .339 & .314 & .286 \\
\hline PR9_3 & .571 & .112 & & .289 & .172 & .348 & .422 \\
\hline PR9_1 & .633 & & .352 & .380 & .239 & .154 & \\
\hline PR9_4 & .490 & & .166 & .140 & .329 & .524 & .268 \\
\hline PR6_4 & .408 & .344 & .160 & .398 & .404 & .192 & .140 \\
\hline PR6_3 & .142 & .809 & .178 & & .120 & .257 & .126 \\
\hline PR6_2 & & .717 & .112 & .205 & & -.178 & \\
\hline PR6_1 & & .601 & & .276 & .365 & .322 & \\
\hline PR7_1 & & .610 & .276 & & .237 & .304 & \\
\hline PR7_3 & .390 & .604 & .229 & .336 & .203 & & .200 \\
\hline PR7_2 & .412 & .597 & .143 & & .270 & & .316 \\
\hline PR5_1 & & .314 & .758 & & .212 & & .259 \\
\hline PR5_4 & .198 & .339 & .760 & .172 & & .120 & \\
\hline PR5_3 & .172 & & .670 & .132 & .119 & .252 & .181 \\
\hline PR5_2 & .322 & .279 & .518 & .362 & .261 & .163 & \\
\hline PR4_1 & & & .431 & .226 & .318 & .479 & \\
\hline PR10_2 & .146 & .194 & .200 & & .800 & .162 & \\
\hline PR10_1 & .263 & .269 & .223 & & .766 & & .121 \\
\hline PR10_4 & & .177 & .131 & .293 & .710 & .548 & .058 \\
\hline PR8_3 & .355 & .123 & .136 & .872 & & .153 & .205 \\
\hline PR8_2 & .265 & .256 & .175 & .680 & .186 & & .127 \\
\hline PR7_4 & .348 & .194 & .483 & .517 & & .228 & \\
\hline PR8_1 & .410 & & .315 & .530 & .247 & .162 & .211 \\
\hline PR4_3 & & .253 & .133 & .230 & & .712 & .112 \\
\hline PR4_2 & & .318 & .305 & -.135 & .105 & .586 & .170 \\
\hline PR10_3 & .184 & .113 & & .205 & .363 & .548 & \\
\hline PR11_4 & .301 & & .146 & & .114 & & .476 \\
\hline PR8_4 & .162 & .203 & .376 & .267 & .191 & & .340 \\
\hline PR4_4 & .385 & & .212 & .226 & .112 & .215 & .730 \\
\hline \%Varianza explicada / componente & 15.40 & 11.20 & 10.80 & 9.70 & 9.50 & 8.00 & 6.40 \\
\hline$\%$ Varianza Acumulada & 15.40 & 26.60 & 37.40 & 47.10 & 56.60 & 64.60 & 71.10 \\
\hline Alfa de Cronbach & 0.92 & 0.87 & 0.87 & 0.88 & 0.89 & 0.73 & 0.71 \\
\hline Prueba KMO & 0.83 & 0.80 & 0.83 & 0.72 & 0.82 & 0.59 & 0.67 \\
\hline
\end{tabular}

Tabla 6. Análisis factorial -matriz de componentes rotados-

De manera detallada, y dado los resultados obtenidos, se puede distinguir un primer factor compuesto por ocho prácticas de recursos humanos socialmente responsables, que de acuerdo a su contenido, se encaminan hacia el logro de una conciliación de la vida profesional y personal del empleado (11.1, 11.2, 11.3, 9.3, 9.2, 9.1, 9.4 y 6.4). Por esta causa, se ha denominado al primer factor gestión de la 
conciliación. El indicador del alfa del Cronbach $(0,92)$ y la KMO (0.83) presentan un buen indicador, entre las prácticas de recursos humanos que conforman este factor.

El segundo factor, observando los ítems que lo conforman $(6.3,6.2,6.1,7.1,7.3$ y 7.2) se puede decir que va orientado a ayudar a construir un clima agradable de trabajo para el empleado, en el que se siente con confianza para participar e intercambiar información con otros mandos, subordinados e iguales, ofreciendo un canal de comunicación no sólo a nivel formal sino informal que posibilite un mejor conocimiento de las redes e interacciones que tienen lugar en la empresa. Considerando las implicaciones y efectos de estas prácticas, este factor ha sido etiquetado como comunicación. Su alfa de Cronbach igual a 0.87 y la $\mathrm{KMO}(0.80)$ proporciona un instrumento fiable de medida para esta política.

El tercer componente agrupa a cinco prácticas de recursos humanos socialmente responsables caracterizadas por una preocupación de la empresa por favorecer el buen desarrollo formativo de los empleados, mostrándose como un método de perfeccionamiento de sus habilidades y competencias, y potenciando su promoción profesional dentro de la organización (5.1, 5.2, 5.3, 5.4 y 4.1). El factor que aglutina a estas prácticas, por su alta coincidencia con la mejora de los conocimientos y habilidades de los empleados, ha sido denominado formación. El alfa de Cronbach proporciona una buena medida de fiabilidad con un indicador de 0.87 y una $\mathrm{KMO}$ de 0.83 .

El cuarto factor viene conformado por cuatro prácticas que ayudan a la implantación de un modelo de gestión que potencie los principios y sinergias de la diversidad e igualdad de oportunidades en la empresa (8.1, 8.2, 8.3 y 7.4). De ello se deduce que este factor podría conceptualizarse como diversidad e igualdad de oportunidades. El alfa de Cronbach pone de manifiesto la fiabilidad de la escala al obtener un 0.87 y una KMO de 0.72 .

El quinto factor que se compone de tres prácticas de recursos humanos socialmente responsables relacionadas con la prevención, seguridad y salud laboral de los empleados (10.1, 10.2, y 10.4), proporciona una alta concordancia con la política de prevención, seguridad y salud laboral identificada en el panel de expertos (método Delphi), de ahí que se proponga conservar la misma denominación. El alfa de Cronbach para este factor nos reporta un buen indicador de consistencia interna de los ítems con un valor de 0.88 y una KMO de 0.82 .

El sexto componente se ha conformado con tres prácticas que advierten de la preocupación constante de la empresa porque los empleados puedan desempeñar sus tareas de forma apropiada en el puesto de trabajo, posibilitando su promoción y desarrollo de una carrera profesional dentro de la empresa (4.2, 4.3 y 10.3). Por estas razones, este factor se ha denominado diseño y adaptación al puesto de trabajo. 
El alfa de Cronbach aunque era algo menor que para el resto de componentes proporcionaba una fiabilidad aceptable con un indicador de 0.73 y una KMO de 0.59 .

El séptimo y último componente se ha conformado a través de tres prácticas (11.4, 8.4 y 4.4). Atendiendo al propósito de estas prácticas, este factor se denominó sistema de información, caracterizado por generar y propagar un mayor conocimiento a lo largo de la empresa, entre sus empleados y la propia estructura y cultura de la misma. Su alfa de Cronbach indica una fiabilidad aceptable con un valor de 0.71 y una KMO de 0.67 .

Confirmada la existencia de siete factores etiquetados como políticas de recursos humanos socialmente responsables, con niveles de fiabilidad y validez aceptables, dado que el porcentaje de varianza total explicada cumple con las expectativas teóricas que sugiere Henson y Roberts (2006), quienes destacan que debe ser superior a un $52 \%$, el siguiente paso es analizar si, igualmente, los ítems pertenecientes a las variables capital humano, social y organizacional se agrupan, cada una de ellas, en un único factor (Tabla 7).

\begin{tabular}{|c|c|}
\hline \multicolumn{2}{|c|}{ Capital humano } \\
\hline $\mathrm{CH} 1$ & 0.71 \\
\hline $\mathrm{CH} 2$ & 0.74 \\
\hline $\mathrm{CH} 3$ & 0.87 \\
\hline $\mathrm{CH} 4$ & 0.77 \\
\hline $\mathrm{CH} 5$ & 0.88 \\
\hline$\%$ de la varianza explicada & 64.5 \\
\hline $\mathrm{KMO}$ & 0.84 \\
\hline \multicolumn{2}{|c|}{ Capital social } \\
\hline CS 1 & 0.79 \\
\hline CS 2 & 0.77 \\
\hline CS 3 & 0.85 \\
\hline CS 4 & 0.77 \\
\hline CS 5 & 0.86 \\
\hline$\%$ de la varianza explicada & 66.4 \\
\hline $\mathrm{KMO}$ & 0.74 \\
\hline \multicolumn{2}{|c|}{ Capital organizacional } \\
\hline $\mathrm{CO} 1$ & 0.39 \\
\hline $\mathrm{CO} 2$ & 0.87 \\
\hline $\mathrm{CO} 3$ & 0.72 \\
\hline $\mathrm{CO} 4$ & 0.95 \\
\hline$\%$ de la varianza explicada & 58.7 \\
\hline $\mathrm{KMO}$ & 0.74 \\
\hline
\end{tabular}

Tabla 7. Análisis factorial para las variables que componen el capital intelectual

Los datos obtenidos demuestran la existencia de un solo factor para cada una de las variables que componen el capital intelectual, resultados que se hallan teóricamente contrastados en la literatura. Los niveles de explicación de la varianza son superiores al 58\% y los niveles de KMO superiores a 0.74 para 
los tres factores generados. Examinados los ítems que componen cada una de las variables del modelo, se puede decir que se han obtenido indicadores apropiados para asegurar la validez de constructo.

Finalmente, con la intención de contrastar cada una de las hipótesis, se procedió a realizar diferentes análisis de regresión múltiple, en los que se examinaron las medidas de bondad de ajuste del modelo (Tabla 8).

\begin{tabular}{|c|c|c|c|c|c|c|c|}
\hline & \multicolumn{2}{|c|}{ Capital humano } & \multicolumn{3}{|c|}{ Capital social } & \multicolumn{2}{|c|}{ Capital organizacional } \\
\hline Variables independientes & H. 2.1 & H.2.2 & H.2.3 & H.2.4 & H.2.5 & H.2.6 & H.2.7 \\
\hline Constante & $-1,127 *$ & $-0,887$ & $-1,122^{*}$ & $-1,184^{*}$ & $-1,045^{*}$ & $-0,823$ & $-0,197$ \\
\hline Ámbito actuación & $0,301 * *$ & $0,293 * *$ & 0,128 & 0,121 & 0,111 & 0,138 & 0,001 \\
\hline Sector & 0,038 & $-0,031$ & 0,268 & 0,301 & 0,269 & 0,112 & 0,008 \\
\hline Tamaño organizativo & 0,000 & $6,557 \mathrm{e}-05$ & $4,558 \mathrm{e}-5$ & $4,001 \mathrm{e}-5$ & $6,6006 \mathrm{e}-6$ & 0,00 & 0,000 \\
\hline Política 1: gestión de la conciliación & & & & & $0,504^{* *}$ & & \\
\hline Política 2: comunicación & & & 0,067 & & & & \\
\hline Política 3: formación & & $0,331 * *$ & & & & & \\
\hline $\begin{array}{l}\text { Política 4: diversidad e igualdad de } \\
\text { oportunidades }\end{array}$ & & & & 0,092 & & & \\
\hline $\begin{array}{l}\text { Política 5: prevención seguridad y } \\
\text { salud laboral }\end{array}$ & & & & & & $0,405^{* *}$ & \\
\hline $\begin{array}{l}\text { Política 6: diseño y adaptación al } \\
\text { puesto de trabajo }\end{array}$ & 0,119 & & & & & & \\
\hline Política 7: sistema de información & & & & & & & 0,183 \\
\hline Estadísticos de contraste & & & & & & & \\
\hline $\mathbf{R}^{2}$ & 0,187 & 0,276 & 0,057 & 0,061 & 0,300 & 0,195 & 0,059 \\
\hline $\mathbf{R}^{2}$ corregido & 0,146 & 0,240 & 0,010 & 0,014 & 0,269 & 0,155 & 0,012 \\
\hline $\mathbf{F}$ & 4,592 & 7,640 & 1,211 & 1,289 & 8,741 & 4,854 & 1,245 \\
\hline
\end{tabular}

Niveles significación: $* \mathrm{p}<0,05$

$* * \mathrm{p}<0,01$

Tabla 8. Resultado de las regresiones lineales para las hipótesis del modelo

A la vista de los resultados que ofrece la Tabla 8, y, atendiendo a los niveles de significación para cada uno de sus parámetros, se aprecia que las Hipótesis 1.1, 1.2 y 1.3 quedan confirmadas atendiendo a sus p-values inferiores a 0.05 . Dicho de otro modo, las políticas de formación, gestión de la conciliación y prevención, seguridad y salud laboral pueden explicar las variaciones en los niveles de capital humano, social y organizacional, respectivamente, en las empresas de la muestra, contrastando como resultado la hipótesis inicial, sobre el impacto de las políticas de recursos humanos socialmente responsables sobre los niveles de capital intelectual de la empresa. A continuación, se explican estos resultados, de manera detallada, para cada una de las hipótesis planteadas.

En lo que a la Hipótesis 1 se refiere, se ha de subrayar que ya ha contrastada y aceptada a través de la confirmación de las tres sub-hipótesis. Con ello, se pone de manifiesto cómo el desarrollar un comportamiento socialmente responsable en el ámbito de la GRH influye de manera directa y 
significativa en la generación de mayores niveles de capital intelectual. A pesar de que el capital intelectual posea una naturaleza intangible, y no pueda cuantificarse en términos monetarios, como ocurra con el desempeño organizativo, que se confirme esta relación alberga gran interés por el grado de competitividad empresarial derivada de mejorar los conocimientos, habilidades y experiencias de los empleados, las redes de relaciones e intercambios que se dan en el seno de las compañías, y los sistemas de información y conocimientos institucionalizados, como resultado de llevar a cabo un comportamiento socialmente responsable en la GRH.

Con carácter adicional, se ha de recordar como se propuso en el marco teórico, la posibilidad de contrastar los efectos independientes de las políticas de recursos humanos socialmente responsables sobre las variables capital humano, social y organizacional. No obstante, en estas hipótesis se realizaron ligeras correcciones atendiendo a las políticas extraídas del análisis factorial. Así, la Hipótesis 1.1 que vinculaba la política de atracción y retención de los trabajadores con el capital humano se reformuló atendiendo al nuevo factor, diseño y adaptación al puesto de trabajo, del que se pretende contrastar igualmente su efecto directo sobre el factor $\mathrm{CH}$. El análisis de regresión lineal múltiple pone de manifiesto que el ámbito de actuación permite explicar parte de la variaciones del capital humano, dado su p-value <0,01, sin embargo la política en cuestión de la hipótesis, adaptación al puesto de trabajo, no presenta influencia significativa sobre los conocimientos, habilidades y experiencias de los trabajadores de las empresas de la muestra. Una posible explicación a este fenómeno puede venir dada porque la conformación del nuevo factor, que integra diversas prácticas de otras políticas de recursos humanos socialmente responsables identificadas en la teoría y validadas en el panel de expertos, pudieran presentar una mayor correlación con otras variables que componen el capital intelectual como el capital social o el organizacional.

En relación con el factor extraído formación no se alteró en contenido con respecto a la política de formación y desarrollo continuo identificada y validada por el panel de expertos, pudiendo hallarse una relación directa y significativa entre dicho factor y el aumento de la variable capital humano, atendiendo a los niveles de significación inferiores a 0.01 , y los coeficientes de determinación $\mathrm{R}^{2}(27.6 \%)$, y $\mathrm{R}^{2}$ ajustado (24\%), que proporcionan un nivel de bondad de ajuste del modelo aceptable. Asimismo, el ámbito de actuación en el que opera la empresa también presentaba una relación significativa en la relación anterior, pudiendo explicar parte de las variaciones en los niveles de capital humano, dado su p-value inferior a 0.01. La justificación de que pueda contrastarse la Hipótesis 1.1 teóricamente puede venir explicada porque la formación está altamente correlacionada con el aumento de los conocimientos, habilidades y experiencias desarrollados por los empleados de la empresa. Adicionalmente, el hecho de que el nuevo factor formación mantenga gran similitud en contenido con 
la política formación y desarrollo continuo previamente formulada y validada en el panel de expertos, confirma el buen diseño teórico de la variable, y el pronóstico de sus potenciales efectos sobre el capital humano.

Con respecto a la Hipótesis 1.2 el factor comunicación, integraba los contenidos casi totales de las prácticas pertenecientes a las políticas de gestión de las relaciones laborales, y comunicación, transparencia y diálogo social anteriormente descritas en la teoría. Atendiendo a los niveles de significación superiores a 0.05 para esta política, y los coeficientes de determinación $\mathrm{R}^{2}$ y $\mathrm{R}^{2}$ ajustado bajos, puede afirmarse que el factor comunicación no influye de manera directa y significativa sobre la generación de un mayor capital social en las empresas de la muestra. A pesar de que el factor fusiona contenidos de políticas relacionadas, que teóricamente pudieran presentar efectos positivos sobre el aumento del capital social, esta combinación pudo distorsionar en parte los efectos sobre la variable dependiente, siendo preciso un mayor análisis de este factor en relación a su posible efecto sobre el capital intelectual de la empresa.

Por otra parte, con respecto al factor diversidad e igualdad de oportunidades no alteró su significado, ni el contenido de las prácticas en el nuevo factor extraído en las empresas de la muestra. Atendiendo a los niveles de significación superiores a 0.05, y los coeficientes de determinación bajos, puede argumentarse que la política de diversidad e igualdad de oportunidades, no permite explicar las variaciones de la variable capital social. A pesar de que el factor, coincide casi exclusivamente con los contenidos de la política definida en la teoría, no influye en el capital social. Una posible explicación de este fenómeno podría venir dada porque integra una práctica independiente de comunicación, que podía distorsionar en parte los efectos sobre el capital social.

En relación al factor extraído, gestión de la conciliación, fusiona casi exclusivamente los contenidos de las prácticas relacionadas con la política de remuneración justa y beneficios sociales, y conciliación de la vida labora y familiar. El análisis de regresión lineal determina, en función de sus niveles de significación inferiores a 0.01 , y los coeficientes de determinación $\mathrm{R}^{2}(30 \%)$ y $\mathrm{R}^{2}(26 \%)$, que la política gestión de la conciliación, influye y por tanto explica las variaciones en el capital social de la empresa, pudiendo aceptarse la Hipótesis 1.2. A pesar de que el factor, combina prácticas relacionadas con la conciliación de la vida laboral y familiar, y la remuneración justa y beneficios sociales, presenta una clara influencia sobre la variable capital social, pudiendo explicar por tanto, la generación de relaciones, intercambios y sistemas de confianza establecidos entre los empleados para las empresas de la muestra derivados de esta política de clara naturaleza social en relación con los intereses y necesidades de los trabajadores. 
La siguiente política examinada, la de prevención, seguridad y salud laboral, la cual coincide prácticamente en contenido con el factor extraído, y por tanto, conserva la misma denominación. Los resultados del análisis de regresión determinan la existencia de una relación significativa entre este factor y el factor capital organizacional, atendiendo a los niveles de significación inferiores a 0.01, y los coeficientes de determinación $\mathrm{R}^{2}(19 \%)$ y $\mathrm{R}^{2}(15 \%)$. Este hecho refuta los planteamientos teóricos, confirmando el buen pronóstico de los efectos potenciales sobre el capital organizacional. La generación de este factor, en relación con el estudio de Youndt y Snell (2004) y su contrastado efecto sobre el capital organizacional es una de las principales novedades de la investigación, ya que dichos autores no indagan en el análisis de cómo las prácticas de prevención de riesgos laborales pueden incidir sobre los niveles de capital intelectual para las empresas.

El último de los factores, sistemas de información, no explicado en la teoría, y como resultado de combinar tres prácticas independientes pertenecientes a diferentes políticas socialmente responsables, no presenta en el análisis de regresión múltiple una influencia significativa sobre el capital organizacional atendiendo a los niveles de significación individual superiores a 0.05 , y los bajos coeficientes de determinación. Este hecho puede venir explicado porque a pesar de sus potenciales efectos sobre el conocimiento institucionalizado de las empresas, estas tres prácticas independientes no son suficientes para explicar la variabilidad del factor capital organizacional.

\section{Conclusiones, limitaciones y líneas futuras}

A nivel académico, los objetivos que se plantearon desde el punto de vista teórico, han sido parcialmente contrastados.

En primer lugar, contribuir a la literatura en RSC y GRH, proponiendo un marco teórico común conformado por diferentes enfoques: institucional y stakeholders, desde el ámbito de la responsabilidad social; y universalista, contingente, configuracional y contextual, desde la disciplina de la GRH. se rubricó el vínculo entre dos disciplinas, RSC y GRH, que hasta hace pocos años han seguido caminos separados en la comunidad académica (Buciuniene \& Kazlauskaite, 2012). De ahí, la novedad y el potencial de este marco combinado para analizar la generación de ventajas competitivas por parte de las empresas.

Como contribución destacada, se concretó la propuesta del sistema de GRH socialmente responsable. Esta idea parte de la base del principio de equifinalidad, examinado en la perspectiva configuracional (Ichniowski \& Shaw, 1999), el cual sostiene que el efecto de combinar diferentes políticas de recursos humanos, bajo una misma orientación, en este caso socialmente responsable, será más eficaz, en lo que 
a la mejora del desempeño organizativo se refiere, y concretamente a la variable implicada en este estudio, el capital intelectual.

Uno de los valores adicionales de este estudio, viene precisamente, de la propia definición y validación de las denominadas políticas y prácticas de recursos humanos socialmente responsables. Para acometer este objetivo, se acudió a varias vías de análisis: literatura, revisión de las memorias de responsabilidad social, estándares internacionales y la opinión y evaluación de estos contenidos previos por parte de un panel de expertos, utilizando para ello la metodología Delphi.

Desde el punto de vista empírico, la prueba de alfa de Cronbach confirmó niveles aceptables de fiabilidad de entre 0.70 y 0.92 para cada una de las variables del modelo de investigación (ocho políticas de recursos humanos socialmente responsables definidas en el panel de expertos; y una configuración de políticas de recursos humanos socialmente responsable conformada por estas ocho políticas). Esta circunstancia proporciona un buen soporte a futuros trabajos académicos que pretendan utilizar estas nuevas variables. De manera específica, la configuración de recursos humanos socialmente responsable propuesta, que abarca a las ocho políticas, reflejó un alfa de Cronbach del $90 \%$ que confirma un buen nivel de fiabilidad de la medida. Este resultado pone de manifiesto que la configuración de recursos humanos propuesta mide realmente comportamientos responsables similares para cada una de sus ocho políticas.

Por otra parte, en cuanto a la validez de los resultados, es preciso destacar que el análisis factorial proporcionó un único factor para cada una de las variables del modelo de investigación (las ocho políticas de recursos humanos socialmente responsables compuestas cada una por cuatro ítems o prácticas de recursos humanos), con una proporción de varianza explicada razonable, albergando todas ellas un significado teórico definido en el panel de expertos. Asimismo, hay que resaltar que todas las políticas definidas en el panel de expertos obtuvieron buenos indicadores de validez para la prueba $\mathrm{KMO}$, y para la proporción de varianza explicada. Con ello, se contrasta la validez, en el ámbito académico, para que estas variables puedan ser analizadas en otros contextos o modelos de investigación.

No obstante, para proporcionar unos resultados más fieles a la realidad de las empresas analizadas, se realizó un análisis factorial a las 32 prácticas de recursos humanos socialmente responsables, para ver si éstas podían agruparse bajo las mismas políticas identificas en el panel de expertos, u otras políticas que pudieran etiquetarse con un significado o sentido teórico diferente. Los resultados del análisis factorial ofrecieron la existencia de siete factores, entendidos como políticas de recursos humanos socialmente responsables, cuyo análisis de los ítems determinó su denominación: 
- gestión de la conciliación;

- comunicación;

- formación;

- diversidad e igualdad de oportunidades;

- $\quad$ prevención, seguridad y salud laboral;

- diseño y adaptación al puesto de trabajo; y

- sistemas de información.

Como puede apreciarse, estas políticas guardaban gran similitud con las ocho políticas socialmente responsables validadas por el panel de expertos. Las diferencias podían venir explicadas porque las empresas podían hacer una interpretación diferente de estas políticas en la praxis, en relación con las teóricamente identificadas por los expertos en el panel. Igualmente, estas políticas, identificadas en las empresas de la muestran, obtuvieron buenos indicadores de fiabilidad y validez, que confirman el buen diseño de las variables, y un pronóstico acertado con alta coincidencia existente entre las opiniones de los expertos académicos, y los resultados observados en estas compañías.

A la hora de testar los efectos directos e indirectos de las políticas y prácticas de recursos humanos socialmente responsables definidas en esta investigación, sobre el desempeño organizativo, y los niveles de capital humano, social y organizacional, se produjeron algunos resultados esperados y ciertas contradicciones teóricas.

En primer lugar, la Hipótesis 1 pudo contrastarse, detrayendo de la misma que uno de los grandes objetivos de la investigación ha sido acometido: demostrar que el desarrollo de una orientación socialmente en las políticas de recursos humanos puede afectar a la generación de valor en la empresa a través de sus niveles de capital intelectual. De esta forma, puede sustentarse, con la presente investigación, que el llevar a cabo un comportamiento más responsable con los empleados a través de siete políticas concretas (gestión de la conciliación, comunicación, formación, diversidad e igualdad de oportunidades, prevención, seguridad y salud laboral, diseño y adaptación al puesto de trabajo y sistemas de información) ayuda a generar conocimientos, habilidades y experiencias entre los empleados (Hipótesis 1.1 contrastada); consolidar una red de relaciones sólida que fomente los intercambios y colaboraciones entre los trabajadores (Hipótesis 1.2 contrastada); y retroalimentando un sistema institucionalizado de conocimiento, del que extraer un mayor resultado operativo por parte de las personas en aspectos que pueden otorgar una ventaja competitiva a las compañías como son el uso de patentes, rutinas y bases de datos (Hipótesis 1.2 contrastada). 
Asimismo, se confirma el fundamento de la perspectiva configuracional de equifinalidad, que confirma en el presente estudio una mayor efectividad por parte de los efectos de una configuración combinada de estas políticas de recursos humanos socialmente responsables sobre los niveles de capital intelectual, en lugar del análisis independiente de cada una de estas políticas sobre esta variable intangible. En este sentido, se advierte que aquellas empresas que apuesten por llevar a cabo una estrategia de responsabilidad social en todas las áreas de su negocio, y más concretamente en la gestión de sus recursos humanos, pueden destacar en el mercado por construir una herramienta potente de atracción y retención de mano de obra cualificada a través de sus políticas de recursos humanos socialmente responsables. Este hecho viene refrendado en el progresivo interés y la creación de rankings profesionales dedicados a medir el comportamiento responsable de las empresas en un área estratégica como es la GRH: The Great Place to Work, MercoPersonas, Empresas TOP para trabajar, Best Employers, Family Responsible Employer Index (IFREI), 100 Most Desirable MBA Employers, The Best Companies for Working Mothers, Top 50 Companies for Diversity, Workplace Equality Index, Top 50 Employers o Corporate Equality Index entre otros.

Así, el hecho de desarrollar políticas de recursos humanos socialmente responsables pueden explicar las diferencias en dotación de determinados recursos de una empresa, especialmente aquellos intangibles, difíciles de adquirir o desarrollar, reproducir y acumular, o ser imitados por los competidores como es el caso del capital humano, el capital social y el capital organizacional. Estos resultados revisten gran utilidad por las implicaciones de estas variables intangibles en el éxito y consolidación de las empresas a largo plazo, yendo más allá de los objetivos económicos a corto plazo.

Entre las líneas futuras el estudio sólo contempla como variables dependientes, las variables capital humano, social y organizacional, ofreciendo la posibilidad de integrar en investigaciones posteriores ratios financieros como la rentabilidad económica y financiera, como plantean Youndt y Snell (2004), y otros ratios no financieros para medir la eficiencia de las políticas de recursos humanos como son la media anual de rotación externa (Huselid, 1995); la media anual de absentismo, coeficiente que recoge el total de horas de no presenciales del trabajador -accidente, baja por enfermedad, licencias, etc. dividido entre el número de horas totales de trabajo; o la percepción de los directores de recursos humanos en relación al grado de compromiso de los empleados derivado de las políticas de recursos humanos. Por ello, el cuestionario podría completarse con la introducción de medidas complementarias de desempeño no financieras, que puedan aportar mayor riqueza y comprensión de los resultados derivados de integrar aspectos de responsabilidad social en la gestión de los recursos humanos.

Entre otras líneas futuras, se plantea la posibilidad de abordar el estudio en las empresas del IBEX-35 dada la implicación de estas empresas a la hora de construir las políticas de recursos humanos 
socialmente responsables, e incluso analizar el uso de políticas y prácticas socialmente responsables en otros rankings de empresas internacionales como las clasificadas por Fortune. Dado que las compañías que pertenecen a estos rankings utilizan estándares de responsabilidad social, que pueden ser objeto de análisis para crear un patrón de políticas de recursos humanos adaptado a una realidad internacional, podría ser un objetivo ambicioso de gran valor para la comunidad académica en materia de RSC y GRH abordar este estudio.

\section{Referencias}

Alama-Salazar, M. (2009). Capital intelectual y resultados empresariales en las empresas de servicios profesionales de España. Tesis Doctoral. Universidad Complutense de Madrid.

Andriessen, D. (2004). IC valuation and measurement: Classifying the state of the art. Journal of Intellectual Capital, 5(2), 230-242. http://dx.doi.org/10.1108/14691930410533669

Astigarraga, E. (2005). El método Delphi. San Sebastián: Universidad de Deusto.

Barreto, I., \& Baden-Fuller, C. (2006). To conform or to perform? Mimetic behaviour, legitimacy-based groups and performance consequences. Journal of Management Studies, 43(7), 1559-1581. http://dx.doi.org/10.1111/j.1467-6486.2006.00620.x

Barney, J.B. (1991). Firm Resources and Sustained Competitive Advantage. Journal of Management, 17(1), 99-120. http://dx.doi.org/10.1177/014920639101700108

Bigné, E., Chumpitaz, R., Andreu, L., \& Swaen, V. (2005). Percepción de la responsabilidad social corporativa: Un análisis cross-cultural. Universia Business Review, 5(1), 14-27.

Brammer, S., Millington, A., \& Rayton, B. (2007). The contribution of corporate social responsibility to organizational commitment. The International Journal of Human Resource Management, 18(10), 1701-1719. http://dx.doi.org/10.1080/09585190701570866

Brewster, C. (1999). Strategic Human Resource Management: The Value of Different Paradigms. Management International Review, 39(3), 45-64. http://dx.doi.org/10.1007/978-3-322-90993-0_5

Brewster, C., Mayrhofer, W., \& Morley, M. (2004). Human Resource Management in Europe -Evidence of Convergence? London: Butterworth-Heineman.

Buciuniene, I., \& Kazlauskaite, R. (2012). The linkage between HRM, CSR and performance outcomes. Baltic Journal of Management, 7(1), 5-24. http://dx.doi.org/10.1108/17465261211195856 
Carroll, A.B. (1999). Corporate social responsibility. Business \& Society, 38(3), 268-295. http://dx.doi.org/10.1177/000765039903800303

Carroll, A.B., \& Shabana, K. (2010). The Business Case for Corporate Social Responsibility: A Review of Concepts, Research and Practice. International Journal of Management Reviews, 12(1), 85-105. http://dx.doi.org/10.1111/j.1468-2370.2009.00275.x

Cohen-Charash, Y., \& Spector, P.E. (2001). The role of justice in organizations: A meta-analysis. Organizational Behavior and Human Decisions Processes, 86(2), 278-321. http://dx.doi.org/10.1006/obhd.2001.2958

Comisión Europea (2011). Estrategia renovada de la UE para 2011-2014 sobre la responsabilidad social de las empresas. Bruselas 25 de Octubre.

Dacin, M.T. (1997). Isomorphism in context: The power and prescription of institutional norms. Academy of Management Journal, 40(1), 46-81. http://dx.doi.org/10.2307/257020

Dacin, M.T., Kostova, Y., \& Roth, K. (2008). Institutional Theory in the Study of Multinational Corporations: A critique and new directions. The Academy of Management Review, 33(4), 994-1006. http://dx.doi.org/10.5465/AMR.2008.34422026

Dahlsrud, A. (2008). How corporate social responsibility is defined: An analysis of 37 definitions. Corporate Social Responsibility and Environmental Management, 15(1), 1-13. http://dx.doi.org/10.1002/csr.132

Delaney, J.T., \& Huselid, M.A. (1996). The impact of human resource management practices on performance in for-profit and nonprofit organizations. Academy of Management Journal, 39(4), 949-969. http://dx.doi.org/10.2307/256718

Delery, J.E., \& Doty, D.H. (1996). Modes of theorizing in strategic human resource management: Tests of universalistic, contingency, and configurational performance predictions. Academy of Management Journal, 39(4), 802-835. http://dx.doi.org/10.2307/256713

Donaldson, T., \& Preston, L.E. (1995). The stakeholder theory of the corporation: Concepts, evidence and implications. The Academy of Management Review, 20(1), 65-91.

Elkington, J. (1998). Cannibals with forks: The triple bottom line of 21st century business. Gabriola Island, British Columbia, Canada: New Society.

Fernández-Allés, M., \& Valle-Cabrera, R. (2006). Reconciling institutional theory with organizational theories: How neoinstitutionalism resolves five paradoxes. Journal of Organizational Change Management, 19(4), 503-517. http://dx.doi.org/10.1108/09534810610676699 
Ferris, G.R., Arthur, M.M., Berkson, H.M., Kaplan, D.M., Harrell-Cook, G., \& Frink, D.D. (1998). Toward a social context theory of the human resource management-organization effectiveness relationship. Human Resource Management Review, 8(3), 235-264. http://dx.doi.org/10.1016/S10534822(98)90004-3

Freeman, R.E. (1984). Strategic management: A stakeholder approach. Boston: Pitman.

Freeman, R.E., Harrison, J.S., Wicks, A.C., Parmar, B.L., \& De Colle, S. (2010). Stakeholder Theory: The State of the Art. Cambridge University Press. http://dx.doi.org/10.1017/cbo9780511815768

Freeman, R.E., \& Liedtka, J. (1991). Corporate Social Responsibility: A Critical Approach. Business Horizons, 34(4), 92-98. http://dx.doi.org/10.1016/0007-6813(91)90012-K

Fuentes-Ganzo, E. (2006). La responsabilidad social corporativa. Su dimension normativa: implicaciones para las empresas españolas. Pecunia, 3, 1-20. http://dx.doi.org/10.18002/pec.v0i3.726

Galbreath, J. (2010). How does corporate social responsibility benefit firms? Evidence from Australia. European Business Review, 22(4), 411-431. http://dx.doi.org/10.1108/09555341011056186

Greenwood, M., \& Anderson, E. (2009). I used to be an employee but now I am a stakeholder: Implications of labelling employees as stakeholders. Asia Pacific Journal of Human Resources, 47(2), 186-200. http://dx.doi.org/10.1177/1038411109105441

Global Reporting Iniatiative (GRI) (2002). Sustainability Reporting Guidelines. GRI, Boston, MA.

Global Reporting Iniatiative (GRI) (2006). Sustainability Reporting Guidelines. GRI, Amsterdam, The Netherlands.

Global Reporting Initiative (GRI) (2011). Sustainability Reporting Guidelines. Disponible online en: https://www.globalreporting.org/resourcelibrary/G3.1-Sustainability-Reporting-Guidelines.pdf

Guest, D.E. (1997). Human resource management and performance: A review and research agenda. International Journal of Human Resource Management, 8(3), 263-276. http://dx.doi.org/10.1080/095851997341630

Guthrie, J. (2001). High-Involvement work practices, turnover, and productivity: Evidence from New Zealand. Academy of Management Journal, 44(1), 180-190. http://dx.doi.org/10.2307/3069345

Henson, R.K., \& Roberts, J.K. (2006). Use of Exploratory Factor Analysis in Published Research: Common Errors and Some Comment on Improved Practice. Educational and Psychological Measurement, 66(3), 393-416. http://dx.doi.org/10.1177/0013164405282485 
Huselid, M.A. (1995). The Impact of Human Resource Management Practices on Turnover, Productivity, and Corporate Financial Performance. Academy of Management Journal, 38(3), 635-672. http://dx.doi.org/10.2307/256741

Ichniowski, C., \& Shaw, K. (1999). The Effects of Human Resource Management Systems on Economic Performance: An International Comparison of U.S. and Japanese Plants. Management Science, 45(5), 704-721. http://dx.doi.org/10.1287/mnsc.45.5.704

Jackson, S.E., \& Schuler, R.S. (1995). Understanding Human Resource Management in the Context of Organizations and their Environments. Annual Review of Psychology, 46(1), 237-264. http://dx.doi.org/10.1146/annurev.ps.46.020195.001321

Kang, S.C., \& Snell, S.A. (2009). Intellectual Capital Architectures and Ambidextrous Learning: A Framework for Human Resource Management. Journal of Management Studies, 46(1), 65-92. http://dx.doi.org/10.1111/j.1467-6486.2008.00776.x

Kim, H.R., Lee, M., Lee, H.T., \& Kim, N.M. (2010). Corporate Social Responsibility and EmployeeCompany Identification. Journal of Business Ethics, 95(4), 557-569. http://dx.doi.org/10.1007/s10551-010$0440-2$

Marimon, F., Alonso-Almeida, M.D.M., Rodríguez, M.D.P., \& Cortez Alejandro, K.A. (2012). The worldwide diffusion of the global reporting initiative: What is the point?. Journal of Cleaner Production, 33, 132-144. http://dx.doi.org/10.1016/j.jclepro.2012.04.017

Mittal, R.K., Sinha, N., \& Singh, A. (2008). An analysis of linkage between economic value added and corporate social responsibility. Management Decision, 46(9), 1437-1443. http://dx.doi.org/10.1108/00251740810912037

Morales-Vallejo, P. (2011). Guia para construir cuestionarios y escalas de actitudes. Publicado en Guatemala: Universidad Rafael Landívar.

Morris, S., \& Snell, S.A. (2011). Intellectual capital configurations and organizational capability: An empirical examination of human resource subunits in the multinational Enterprise. Journal of International Business Studies, 42(1), 805-827. http://dx.doi.org/10.1057/jibs.2011.14

Nahapiet, J., \& Ghoshal, S. (1998). Social capital, intellectual capital, and the organizational advantage. The Academy of Management Review, 23(2), 242-266.

Peloza, J., \& Shang, J. (2011). How can corporate social responsibility activities create value for stakeholders? A systematic review. Journal of the Academy of Marketing Science, 39(1), 117-135. http://dx.doi.org/10.1007/s11747-010-0213-6 
Pérez-López, C. (2009). Tecnicas estadisticas multivariantes con SPSS. Madrid: Garceta grupo editorial.

Pfeffer, J. (1998). The Human Equation: Building Profits by Putting People First. Boston: Harvard Business Press.

Phillips, R., Freeman, R.E., \& Wicks, A.C. (2003). What Stakeholder Theory is Not. Business Ethics Quarterly, 13(4), 479-502. http://dx.doi.org/10.5840/beq200313434

Shauki, E. (2011). Perceptions on corporate social responsibility: A study in capturing public confidence. Corporate Social Responsibility and Environmental Management, 18(3), 200-208. http://dx.doi.org/10.1002/csr.267

Scherer, A.G., \& Palazzo, G. (2011). The New Political Role of Business in a Globalized World: A Review of a New Perspective on CSR and its Implications for the Firm, Governance, and Democracy. Journal of Management Studies, 48(4), 899-931. http://dx.doi.org/10.1111/j.14676486.2010.00950.x

Scott, W.R. (2007). Institutions and Organizations. Thousand Oaks: Sage Publications.

Surroca, J., Tribó, J., \& Waddock, S. (2010). Corporate responsibility and financial performance: The role of intangible resources. Strategic Management Journal, 31(5), 1-49. http://dx.doi.org/10.1002/smj.820

Svensson, G.R., \& Wood, G. (2011). A conceptual framework of corporate and business ethics across organizations: Structures, processes and performance. The Learning Organization, 18(1), 21-35. http://dx.doi.org/10.1108/09696471111095975

Tzaffir, S. (2006). A universalistic perspective for explaining the relationship between HRM practices and firm performance at different points in time. Journal of Managerial Psychology, 21, 109-130. http://dx.doi.org/10.1108/02683940610650730

Urgal, B., Quintás, M.Á., \& Arévalo-Tomé, R. (2011). Conocimiento tecnológico, capacidad de innovación y desempeño innovador: el rol moderador del ambiente interno de la empresa. Cuadernos de Economía y Dirección de la Empresa, 14, 53-66. http://dx.doi.org/10.1016/j.cede.2011.01.004

Walton, R.E., (1985). From control to commitment in the workplace. Harvard Business Review, MarchApril, 77-84.

Werther, W., \& Chandler, D. (2010). Strategic Corporate Social Responsibility. Stakeholders in a Global Environment. Sage Publications.

Youndt, M.A., \& Snell, S.A. (2004). Human Resource Configurations, Intellectual Capital, and Organizational Performance. Journal of Managerial Issues, 16(3), 337-360. 
Zéghal, D., \& Maaloul, A. (2010). Analysing value added as an indicator of intellectual capital and its consequences on company performance. Journal of Intellectual Capital, 11(1), 39-60. http://dx.doi.org/10.1108/14691931011013325

Intangible Capital, 2016 (www.intangiblecapital.org)

Article's contents are provided on an Attribution-Non Commercial 3.0 Creative commons license. Readers are allowed to copy, distribute and communicate article's contents, provided the author's and Intangible Capital's names are included. It must not be used for commercial purposes. To see the complete license contents, please visit http://creativecommons.org/licenses/by-nc/3.0/. 